\title{
Deafness-related plasticity in the inferior colliculus: gene expression profiling following removal of peripheral activity
}

\author{
Avril Genene Holt,* Mikiya Asako, ${ }^{\dagger}$ Catherine A. Lomax, ${ }^{*}$ James W. MacDonald, + Ling Tong, ${ }^{*}$ \\ Margaret I. Lomax*, ${ }^{*}$ and Richard A. Altschuler*, \\ *Kresge Hearing Research Institute, Department of Otolaryngology/Head Neck Surgery, University of Michigan, Ann Arbor, \\ Michigan, USA \\ $\dagger$ Department of Otolaryngology/Head Neck Surgery, Kansai Medical University, Osaka, Japan \\ $\$$ University of Michigan Comprehensive Cancer Center Microarray Core and §Department of Cell and Developmental Biology, \\ University of Michigan, Ann Arbor, Michigan, USA
}

\begin{abstract}
The inferior colliculus (IC) is a major center of integration in the ascending as well as descending auditory pathways, where both excitatory and inhibitory amino acid neurotransmitters play a key role. When normal input to the auditory system is decreased, the balance between excitation and inhibition in the IC is disturbed. We examined global changes in gene expression in the rat IC 3 and 21 days following bilateral deafening, using Affymetrix GeneChip arrays and focused our analysis on changes in expression of neurotransmission-related genes. Over 1400 probe sets in the Affymetrix Rat Genome U34A Array were identified as genes that were differentially expressed. These genes encoded proteins previously reported to change as a consequence of deafness, such as calbindin, as well as proteins not previously reported to be modulated by deafness, such as clathrin. A subset of 19 differentially expressed genes was further examined using quantitative RT-PCR at 3,21 and 90 days following deafness. These included several GABA, glycine, glutamate receptor and neuropeptide-related genes.
\end{abstract}

Expression of genes for GABA-A receptor subunits $\beta 2, \beta 3$, and $\gamma 2$, plus ionotropic glutamate receptor subunits AMPA 2, AMPA 3, and kainate 2, increased at all three times. Expression of glycine receptor $\alpha 1$ initially declined and then later increased, while $\alpha 2$ increased sharply at 21 days. Glycine receptor $\alpha 3$ increased between 3 and 21 days, but decreased at 90 days. Of the neuropeptide-related genes tested with qRT-PCR, tyrosine hydroxylase decreased approximately $50 \%$ at all times tested. Serotonin receptor $2 \mathrm{C}$ increased at 3, 21, and 90 days. The $5 \mathrm{~B}$ serotonin receptor decreased at 3 and 21 days and returned to normal by 90 days. Of the genes tested with qRT-PCR, only glycine receptor $\alpha 2$ and serotonin receptor $5 B$ returned to normal levels of expression at 90 days. Changes in GABA receptor $\beta 3$, GABA receptor $\gamma 2$, glutamate receptor $2 / 3$, enkephalin, and tyrosine hydroxylase were further confirmed using immunocytochemistry.

Keywords: auditory brainstem, immunocytochemistry, microarray, neurotransmitter, RT-PCR.

J. Neurochem. (2005) 93, 1069-1086.
Plasticity in the mature mammalian central nervous system is often induced by changes in neuronal activity. This response, called 'activity-dependent plasticity', can involve changes in amino acid neurotransmitters and receptors which, in turn, can reshape neuronal responses and information processing.

Resubmitted manuscript received February 17, 2005; accepted March 1, 2005.

Address correspondence and reprint requests to Dr Avril Genene Holt, KHRI, Department of Otolaryngology, The University of Michigan, 1301 East Ann Street, Ann Arbor, MI, USA.

E-mail: avrilhol@umich.edu
Abbreviations used: ABR, auditory brainstem response; BDNF, Brain derived neurotrophic factor; $\mathrm{BMP}$, bone morphogenetic protein; $\mathrm{Ct}$, cycle threshold; DEPC, diethyl pyrocarbonate; Egr, early growth response; EST, expressed sequence tag; FDR, false discovery rate; glns, glutamine synthetase; GO, gene ontology; 5-HT, serotonin; IC, inferior colliculus; MAP, microtubule-associated protein; MES, 2-(N-morpholino) ethane sulphonic acid; MM, mismatch; PBS, phosphate-buffered saline; PNOC, Prepronociceptin; PKC, protein kinase C; PM, perfect match; PENK, pre-proenkephalin; qRT-PCR, quantitative RT-PCR; RMA, robust multiarray average; SAM, Statistical Analysis of Microarrays; SNAP, synaptosomal-associated protein; SSPE, Saline Sodium Phosphate EDTA; TH, tyrosine hydroxylase. 
The auditory system provides an excellent model for examining activity-dependent plasticity, because the level of neuronal activity can be easily manipulated. Deafness (full or partial) and noise over-stimulation have been shown to lead to plastic changes in the mature central auditory pathways (Syka 2002; Moller 2005). Changes that have been reported following deafness include changes in the tonotopic map (Robertson et al. 1989; Rajan et al. 1993), in cell size (Sie and Rubel 1992; Dodson et al. 1994; Lustig et al. 1994; Lesperance et al. 1995; Willott and Bross 1996; Moore et al. 1997; Niparko and Finger 1997; Araki et al. 1998; Edmonds et al. 1999; Niparko 1999; Nishiyama et al. 2000), changes in synaptic contacts and synapse morphology (Kazee et al. 1995; Huchton et al. 1997; Ryugo et al. 1997; Niparko 1999; Russell and Moore 2002; Lee et al. 2003), in neurotransmitters and receptors as well as their release, uptake and binding (Caspary et al. 1995; Milbrandt et al. 2000; Potashner et al. 2000; Vale and Sanes 2002), in ion channels (Storey et al. 2002; Mhatre et al. 2004), in transcription factors (Illing et al. 1999; Illing and Michler 2001; von Hehn et al. 2004), in oxygen reactive species (Ohlemiller and Dugan 1999; Ohlemiller et al. 1999; Shi et al. 2002), and in stress response molecules (Myers et al. 1992; Billings et al. 1995; Verstreken et al. 1996; Oh et al. 2000; Van Campen et al. 2002; Wang et al. 2002; Yeom et al. 2003). These changes can lead to problems such as poor speech perception and tinnitus when there is partial or incomplete deafness and can influence the efficacy of cochlear prostheses following profound deafness.

An auditory brainstem region in which activity-dependent plastic changes have been well characterized is the inferior colliculus (IC), a major center of integration in the ascending as well as descending auditory pathways. Following deafness, there is a marked change in the balance of excitation and inhibition, resulting in changes in synaptic strength, inhibitory strength and evoked responses (Bledsoe et al. 1995; Wang et al. 1996; Mossop et al. 2000; Vale and Sanes 2002) These are associated with changes in inhibitory and excitatory amino acids and their receptors, particularly with changes in the production (Raza et al. 1994; Milbrandt et al. 2000; Mossop et al. 2000) and release (Bledsoe et al. 1995; Caspary et al. 1995) of GABA, as well as changes in GABA receptors (Caspary et al. 1995; Milbrandt et al. 2000; Vale and Sanes 2000).

Given the large and varied number of activity-dependent changes reported in the auditory brainstem following deafness, changes in expression for a large number of genes might be expected in the IC following deafness. Genes associated with amino acid neurotransmission and its regulation would be specific candidates for differential expression. Gene microarrays provide a method of screening thousands of genes simultaneously. Such an analysis can test multiple amino acid neurotransmission genes, identifying new genes that show changes, while confirming those already shown by other methods. By using this method, we can also identify genes associated with other known deafness-related changes, as well as identify changes in expression of genes associated with novel processes.

We therefore used Affymetrix rat U34A GeneChip arrays to examine changes in gene expression in the rat IC at two times following bilateral deafening. As expected, many genes encoding proteins involved in neurotransmission showed changes in expression. We verified a subset of these genes using quantitative RT-PCR (qRT-PCR) and immunocytochemistry. We were also able to identify genes associated with other known changes with deafness as well as genes that have not previously been shown to be activity dependent.

\section{Materials and methods}

\section{Experimental design}

Rats were checked for normal hearing by auditory brainstem response (ABR) prior to the study and were randomly assigned to either a group that received bilateral deafening or to an untreated, normal-hearing group. Treated rats and the age-matched controls were processed for gene microarrays at 3 and 21 days following deafness and for qRT-PCR and immunocytochemistry at 3, 21 and 90 days following deafening. These time points were chosen based on previous studies showing either transient or permanent changes in neurotransmitter and receptors at these times (Bledsoe et al. 1995; Sato et al. 2000). For gene microarray experiments, rats were randomly divided into three groups containing 18 animals per group: Group 1, normal hearing; group 2, bilaterally deafened by cochlear ablation and assessed at 3 days following deafening; and group 3, bilaterally deafened by cochlear ablation and assessed at 21 days following deafening. Each of these three groups was further divided into six subgroups containing three animals each. Therefore, six experimental replicates were performed per group, with the pooled inferior colliculi from three animals comprising one replicate. Thus, there were six biological replicates per experimental group, three groups and 18 total chips assessed. For qRT-PCR one of the six replicates from each group was randomly selected and run in triplicate on three separate occasions for each gene product examined ( 21 in all). For immunocytochemistry, 12 additional animals were analyzed, four in the normal group, three in the 3-days deafened group, two in the 21-days deafened group, and three in the 90-days deafened group.

\section{Cochlear ablation}

Male Sprague-Dawley rats obtained from Charles River Laboratories (Wilmington, MA, USA), were maintained on a 12-h reversed light-dark cycle and had free access to food and water. All studies were approved by the University Committee on the Use and Care of Animals. Rats weighing 185-275 g were deeply anesthetized with a mixture of ketamine $(75 \mathrm{mg} / \mathrm{kg})$ and xylazine $(8 \mathrm{mg} / \mathrm{kg})$. ABR thresholds were measured at frequencies of 2,10 and $20 \mathrm{kHz}$ from 0 to $100 \mathrm{~dB}$ before surgery to confirm that all animals had normal hearing. Animals were bilaterally deafened by mechanical ablation of the cochlea. Hearing thresholds were again determined on anesthetized animals by ABR 3, 21 or 90 days following ablation, 
to assess the degree of hearing loss. Only animals that sustained a threshold shift of $80 \mathrm{~dB}$ or greater were included in the study. This criterion for deafness was to ensure a homogenous group of deafened animals.

\section{RNA isolation}

Rats were anesthetized with a lethal dose $(0.8-1 \mathrm{~mL})$ of Fatal Plus (Vortech Pharmaceuticals, Dearborn, MI, USA) and decapitated. Brains were rapidly removed and the right and left IC dissected away from the remaining midbrain with fine-tipped forceps and placed in RNAlater (Ambion, Austin, TX, USA). Tissues were homogenized in Trizol (Invitrogen, Carlsbad, CA, USA) for $10 \mathrm{~s}$ with a Tissue-Tearor ${ }^{\mathrm{TM}}$ homogenizer (Biospec Products Inc., Bartlesville, OK, USA). RNA was isolated using a modification of the standard Trizol protocol. Briefly, chloroform was added to the homogenate, vortexed briefly, and centrifuged at $14000 \mathrm{~g}$. The aqueous phase was transferred to a Phase Lock Gel (heavy) tube (Eppendorf/Brinkmann, Westbury, NY, USA) and extracted with acid phenol : chloroform $(1: 1)$. The aqueous phase was decanted and RNA was precipitated with isopropanol. Contaminants were removed with RNeasy mini-spin columns (Qiagen, Chatsworth, CA, USA). RNA was eluted in $100 \mu \mathrm{L}$ of diethyl pyrocarbonate (DEPC) treated water. RNA concentration was determined by UV spectrophotometry. RNA quality was assessed on an RNA 6000 Nano LabChip (Agilent, Palo Alto, CA, USA) using an Agilent 2100 Bioanalyzer, to assess the integrity of the $18 \mathrm{~S}$ and $28 \mathrm{~S}$ rRNA bands.

\section{Hybridization of Affymetrix GeneChips}

This study utilized high-density oligonucleotide microarrays (GeneChips, Affymetrix, Santa Clara, CA, USA) that detect the expression levels of 8799 known genes and expressed sequence tags (ESTs; Rat Genome U34A Array). Preparation of cRNA, hybridization and scanning of the arrays were performed according to manufacturer's protocols. Briefly, $5 \mu \mathrm{g}$ of total RNA was used to generate doublestranded cDNA by reverse transcription using a cDNA synthesis kit (Superscript Choice System, Gibco-BRL, Rockville, MD, USA) that employs an oligo $(\mathrm{dT})_{24}$ primer containing a T7 RNA polymerase promoter $5^{\prime}$ to the poly(dT) (Genset, La Jolla, CA, USA), followed by second-strand synthesis. Biotin-labeled cRNA was prepared from the double-stranded cDNA by in vitro transcription with T7 RNA polymerase in the presence of biotin-11-CTP and biotin-16-UTP (Enzo, Farmingdale, NY, USA), then purified over RNeasy columns (Qiagen). Fifteen micrograms of cRNA was fragmented at $94^{\circ} \mathrm{C}$ for $35 \mathrm{~min}$ in $40 \mathrm{~mm}$ Tris-acetate ( $\mathrm{pH} \mathrm{8.1)}, 100 \mathrm{~mm}$ potassium acetate, and $30 \mathrm{~mm}$ magnesium acetate, then added to $300 \mu \mathrm{L}$ of hybridization cocktail (100 mM MES, $1 \mathrm{~m} \mathrm{NaCl}, 20 \mathrm{~mm}$ EDTA, 0.01\% Tween 20) containing $0.1 \mathrm{mg} / \mathrm{mL}$ herring sperm DNA (Promega, Madison, WI, USA), and $500 \mu \mathrm{L} / \mathrm{mL}$ acetylated bovine serum albumin (BSA; Gibco-BRL). Prior to hybridization, the cocktails were heated to $94^{\circ} \mathrm{C}$ for $5 \mathrm{~min}$, equilibrated at $45^{\circ} \mathrm{C}$ for $5 \mathrm{~min}$, then centrifuged $(16000 \mathrm{~g})$ at room temperature $\left(27^{\circ} \mathrm{C}\right)$ for $5 \mathrm{~min}$. Aliquots of this hybridization cocktail containing $10 \mu \mathrm{g}$ of fragmented cRNA were hybridized to HuGeneFL arrays at $45^{\circ} \mathrm{C}$ for $16 \mathrm{~h}$ in a rotisserie oven at 60 r.p.m. The arrays were washed under non-stringent conditions $(6 \times$ Saline Sodium Phosphate EDTA (SSPE) at $\left.25^{\circ} \mathrm{C}\right)$, followed by a stringent wash [100 mm 2-(Nmorpholino) ethane sulphonic Acid, MES) (pH 6.7), $0.1 \mathrm{~m} \mathrm{NaCl}$, $0.01 \%$ Tween 20 at $50^{\circ} \mathrm{C}$ ], then stained with streptavidin-phyco- erythrin (Molecular Probes, Eugene, OR, USA), washed with $6 \times$ SSPE, incubated with biotinylated anti-streptavidin IgG, stained again with streptavidin-phycoerythrin, and washed again with $6 \times$ SSPE. Arrays were scanned with the GeneArray scanner (Affymetrix) and image analysis was performed with GeneChip software (Affymetrix).

\section{Microarray data analysis}

Affymetrix U34A GeneChips contain a set a set 16 pairs of short (25-mer) oligonucleotide probes for each gene (a probe set). The paired probes consist of a 'perfect match' (PM) probe that is identical to a particular sequence of the gene and a 'mismatch' (MM) probe that has the central base switched with its complement. PM probes are used to estimate transcript abundance, whereas MM probes are intended to provide a measure of background binding for each PM probe. Overall transcript abundance for each gene is estimated by calculating a summary statistic for each probeset (an 'expression value'). There are several methods for computing expression values [MAS5, dChip, robust multiarray average (RMA), etc.]; we chose to use an RMA as implemented in the 'affy' package of Bioconductor (http://www.bioconductor.org). RMA performs three operations: probe-specific background correction to compensate for non-specific binding using PM distribution rather than PMMM value; probe-level multichip quantile normalization to unify PM distributions across all chips; and robust probe-set summary of the log-normalized probe-level data by median polishing. This method is based on recent studies that used dilution and spike-in experiments, adding known amount of specific transcripts to the preparation, to evaluate different methods of calculating intensity values and normalizing GeneChip data. RMA was directly compared with other GeneChip analysis software such as dChip or MAS5 (Irizarry et al. 2003a,b). These studies found that RMA gave the most accurate representation of 'known' datasets.

\section{Statistical analysis}

Statistical Analysis of Microarrays (SAM; http://www-stat.stanford.edu/ tibs/SAM) was used to perform two-sample $t$-tests on the $\log$ transformed (log base 2) intensity values obtained from 18 GeneChips (six biological replicates from each of three experimental groups). By permuting the data to estimate the percentage of genes identified at random, a user of SAM can calculate a false discovery rate (FDR), the probability that the change in expression of a given gene is erroneously called significant, and thereby assign statistical significance to differences in intensity values across experimental groups (Tusher et al. 2001). Genes with an FDR of 5\% or less were considered significant in the current study.

\section{Quantitative RT-PCR}

A subset of significantly expressed genes was selected for further study, based on the importance of amino acid neurotransmitters and neuropeptides in the ascending auditory pathways. Real-time PCR was performed on a randomly selected pool of RNA (from pools used in GeneChip experiments) 3 and 21 days following cochlear ablation. The 90-day group consisted of three pools of mRNA, each derived from three animals. cDNA was generated from $1 \mu \mathrm{g}$ of total RNA using Superscript II (Invitrogen). The cDNA was diluted to $200 \mu \mathrm{L}$ and $2.5 \mu \mathrm{L}$ was used for each real-time PCR reaction. Realtime PCR reactions were performed using Assays-by-Design 
TaqMan MGB assays (Applied Biosystems, Foster City, CA, USA), which use $5^{\prime}$ nuclease chemistry with two unlabeled PCR primers (Table S1; $900 \mu \mathrm{M}$ each) and an FAM dye-labeled TaqMan minor groove binder (MGB) probe $(250 \mu \mathrm{M})$, and TaqMan Universal PCR Master Mix. Reactions were performed on an ABI Prism 7900, and results were analyzed using ABI Prism 7900 Sequence Detection System software (Applied Biosystems).

We tested 19 neurotransmission-related genes at the 3-, 21- and 90-day time points in triplicate. These genes were GABA-A receptors $\beta 2, \beta 3, \gamma 1, \gamma 2$; glutamate decarboxylase 2 ; glycine $\alpha 1, \alpha 2$, a3; glutamate receptors AMPA 2 (GluR 2), AMPA 3 (GluR 3); glutamine synthetase 1 (glns); glutaminase (gls); glutamate receptor kainate 2 (GluR K2); 5-hydroxytryptamine (serotonin) receptors $5 \mathrm{~B}, 2 \mathrm{C}$; pre-proenkephalin; pre-pronociceptin (neuropeptide nociceptin); activity and neurotransmitter-induced early gene protein 4 (ania-4); and tyrosine hydroxylase (TH).

We used the $2^{-\Delta} \Delta_{2} \mathrm{Ct}$ method to calculate the fold change in gene expression (Livak and Schmittgen 2001). For each gene at each time point, we determined the cycle threshold $(\mathrm{Ct})$, the cycle number at which PCR products are increasing exponentially. To normalize the data, the threshold value for ribosomal subunit S16 was subtracted from threshold values for each gene at each time point $\left(\Delta_{1}\right)$. Then the threshold value of the control group for each gene was subtracted from the experimental threshold value $\left(\Delta_{2}\right)$. The final value was then expressed as logarithm to base 2. Using this formula

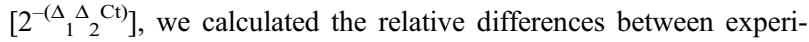
mental and control groups as fold change. The average value of triplicate PCR reactions was normalized to the average value for the S16 ribosomal protein for each sample and then compared with the expression value of the control group.

\section{Immunocytochemistry}

From the group of genes confirmed by qRT-PCR, we selected five genes to determine the cellular localization and distribution of their products in the IC, using immunocytochemistry. Two of these genes, $\mathrm{TH}$ and pre-proenkephalin, showed decreases and three genes, GluR 2/3, GABA-A receptor subunit $\beta 3$ and subunit $\gamma 2$, increased in expression. The distribution of labeled neurons and processes were examined in a qualitative manner in sections from the brachium to the mid rostro-caudal region of the IC. Normal animals $(n=4)$ were compared with eight deafened animals (three 3-day deaf, two 21-day deaf, three 90-day deaf). Animals were anesthetized with Fatal Plus $(0.8-1 \mathrm{~mL})$ and then received vascular perfusion with phosphate buffer followed by a fixative containing $4 \%$ paraformaldehyde in phosphate buffer. Brains were removed and post-fixed for $2 \mathrm{~h}$ in the same fixative. Brains were then rinsed in phosphate-buffered saline (PBS) and placed in $10 \%$ sucrose in PBS for $12-16 \mathrm{~h}$ at $4^{\circ} \mathrm{C}$. The auditory brainstem was then rapidly frozen onto a cryostat chuck using OCT compound (Fisher Scientific, Pitsburgh, PA, USA) and $12 \mu \mathrm{m}$ frozen coronal sections were cut through the IC. Sections were mounted on Fisher Plus slides and antibodies were used to localize the protein products of these five differentially expressed genes within the IC.

Cryostat sections were incubated with a primary antibody, TH (Novus Biologicals, Littleton, CO, USA, $1: 400$ ), pre-proenkephalin (PPENK; Fitzgerald Industries, Concord, MA, USA; $1: 100$ ), GluR 2/3 (Chemicon, Temecula, CA, USA; $1: 50$ ), GABA $\beta 3$ (Santa Cruz Biotechnology, Santa Cruz, CA, USA; $1: 50$ ), or
GABA $\gamma 2$ (Alomone Laboratories, Jerusalem, Israel; $1: 4000$ ) and normal serum from the species in which the secondary antibody was raised (donkey or goat; $1: 200$; Jackson Laboratories Bar Harbor, ME, USA) in PBS with $0.3 \%$ triton X-100 for $24 \mathrm{~h}$ at $4^{\circ} \mathrm{C}$ in a humid chamber. All subsequent incubations and rinses (three times for $5 \mathrm{~min}$ in PBS) were carried out at room temperature. The sections were then rinsed and incubated for $1 \mathrm{~h}$ with Alexa fluor 594 donkey anti-goat $(1: 100)$ or Alexa fluor 568 goat anti-rabbit $(1: 100)$ secondary antibody (Molecular Probes) in $0.3 \%$ triton X-100. After rinsing, slides were coverslipped using gel/mount (Biomedia Corp., Foster City, CA, USA).

\section{Histological analysis}

Images of immunoreactive cells, fibers, and puncta in the IC were obtained from sections using a Zeiss LSM confocal microscope. The characteristics: somatic, dendritic, punctate, as well as the amount and location of the immunoreactive label within the IC, were noted for each experimental group, and a blind qualitative assessment was made by two investigators. For each antibody, a $z$-series was collected for each experimental group studied. The $z$-series was then montaged and one maximum projection image compiled.

\section{Results}

\section{Identification of differentially expressed genes following deafening}

From the 8799 probe sets interrogated on the Affymetrix GeneChips, we found over 1400 probe sets that showed differential expression at either 3 or 21 days following deafness, with a false discovery rate (FDR) of $5 \%$ or less. Of these, 411 showed increased expression after 3 days of deafness, and 38 had decreased expression (Table S2). By 21 days following deafness, 700 probe sets had increased expression and 331 decreased (Table S3). With the additional restriction of a twofold or greater increase in expression, 38 probe sets met this criterion at 3 days (Table 1) and 57 probe sets at 21 days (Table 2). With the additional restriction of a decrease of approximately $20 \%$ or more, 34 probe sets showed decreased expression 3 days following deafness (Table 3) and 104 decreased at 21 days following deafness (Table 4).

Genes showing the largest increase in expression included several that encode proteins involved in neurotransmission, such as synaptosomal-associated protein (SNAP 25), GABA-A receptor epsilon, and microtubule-associated protein 2 (MAP2; Tables 1 and 2). Genes with the greatest decrease in expression included pre-proenkephlin (PENK), early growth response 1 (ERG1), and activity-regulated cytoskeletal-associated protein (ARC; Tables 3 and 4). Among those probe sets showing large increases or decreases in expression, several were 'unknowns', or genes that have not yet been identified. Of the 1480 genes showing significant differential expression, 83 were classified as 
Table 1 Genes with greater than 2 fold increase in expression 3 days following deafness

\begin{tabular}{|c|c|c|c|c|}
\hline Gene Title & UniGene ID & Fold Change & q-value (\%) & Probe Set ID \\
\hline Unknown & Unknown & 3.97 & 0.40 & M13101cds_f_at \\
\hline aquaporin 4 & Rn.90091 & 3.97 & 0.40 & U14007_at \\
\hline Unknown & Unknown & 3.77 & 0.40 & U83119_f_at \\
\hline LINE retrotransposable element 3 & Unknown & 3.75 & 0.40 & M13100cds\#6_f_at \\
\hline Unknown & Unknown & 3.68 & 0.40 & X53581cds\#5_f_at \\
\hline Unknown & Unknown & 3.65 & 0.40 & X05472cds\#1_s_at \\
\hline Unknown & Unknown & 3.36 & 0.40 & X61295cds_s_at \\
\hline LINE retrotransposable element 3 & Unknown & 3.35 & 0.40 & M13100cds\#2_s_at \\
\hline visinin-like 1 & Rn.105934 & 3.22 & 0.40 & D10666_at \\
\hline Unknown & Unknown & 3.17 & 0.40 & X07686cds_s_at \\
\hline synaptosomal-associated protein & Rn.107689 & 3.09 & 0.40 & AB003991_g_at \\
\hline LINE retrotransposable element 3 & Unknown & 2.92 & 0.40 & M13100cds\#4_f_at \\
\hline synaptosomal-associated protein & Rn.107689 & 2.84 & 0.40 & AB003992_s_at \\
\hline synaptosomal-associated protein & Rn.107689 & 2.59 & 0.40 & AB003991_at \\
\hline $\begin{array}{l}\text { Similar to pinin; DNA segment, Chr } 12 \text {, } \\
\text { ERATO Doi } 512 \text {, expressed } \\
\text { (LOC368070), mRNA }\end{array}$ & Rn.38987 & 2.59 & 0.40 & rc_Al639151_at \\
\hline LINE retrotransposable element 3 & Unknown & 2.54 & 0.40 & M13100cds\#3_f_at \\
\hline LINE retrotransposable element 3 & Unknown & 2.53 & 0.40 & M13100cds\#5_s_at \\
\hline $\begin{array}{l}\text { Transcribed seq. with moderate similarity to } \\
\text { protein pdb:1LBG (E. coli) B Chain B, } \\
\text { Lactose Operon Repressor Bound To 21-Base } \\
\text { Pair Symmetric Operator Dna, } \\
\text { Alpha Carbons Only }\end{array}$ & Rn.24387 & 2.36 & 0.40 & rc_AA891476_at \\
\hline cadherin 22 & Rn. 108785 & 2.35 & 0.40 & D83349_at \\
\hline $\begin{array}{l}\text { Similar to RNA-binding region (RNP1, RRM) } \\
\text { containing 2; splicing factor (CC1.3); coactivator of } \\
\text { activating protein-1 and estrogen } \\
\text { receptors (LOC362251), mRNA }\end{array}$ & Rn.8555 & 2.33 & 0.40 & rc_AA800126_at \\
\hline Unknown & Unknown & 2.31 & 0.40 & X53581cds\#3_f_at \\
\hline $\begin{array}{l}\text { Similar to heterogeneous nuclear } \\
\text { ribonucleoprotein A2/B1 (LOC362361), mRNA }\end{array}$ & Rn.4057 & 2.25 & 0.40 & rc_AA799511_g_at \\
\hline Ac1054 mRNA, complete cds & Rn.3412 & 2.25 & 0.40 & rc_AA893212_at \\
\hline gamma-aminobutyric acid A receptor, alpha 1 & Unknown & 2.18 & 0.40 & L08490cds_at \\
\hline Transcribed sequences & Rn.25117 & 2.18 & 0.40 & rc_AA799804_at \\
\hline microtubule-associated protein 2 & Rn.10484 & 2.17 & 0.40 & X17682_s_at \\
\hline Transcribed sequences & Rn.98479 & 2.15 & 0.40 & rc_AA874873_at \\
\hline Similar to N-terminal aceyltransferase 1 (LOC310399), mRNA & Rn.12587 & 2.14 & 2.89 & rc_Al177404_at \\
\hline microtubule-associated protein 2 & Rn.10484 & 2.13 & 0.40 & X53455cds_s_at \\
\hline catalase & Rn.3001 & 2.07 & 0.40 & rc_AA926149_g_at \\
\hline $\begin{array}{l}\text { Similar to heterogeneous nuclear } \\
\text { ribonucleoprotein A2/B1 (LOC362361), mRNA }\end{array}$ & Rn.4057 & 2.06 & 0.40 & rc_AA799511_at \\
\hline ectonucleotide pyrophosphatase/phosphodiesterase 2 & Rn.20403 & 2.06 & 0.40 & D28560_at \\
\hline Nclone10 mRNA & Rn.32307 & 2.05 & 0.40 & rc_Al071866_s_at \\
\hline diacylglycerol kinase, beta & Rn.11413 & 2.04 & 0.71 & rc_AA818983_at \\
\hline LINE retrotransposable element 3 & Unknown & 2.04 & 0.40 & M13100cds\#1_g_at \\
\hline chimerin (chimaerin) 1 & Rn.11166 & 2.01 & 1.39 & X67250_at \\
\hline solute carrier family 3 , member 1 & Rn.11196 & 2.01 & 0.40 & M80804_s_at \\
\hline Transcribed sequences & Rn.22663 & 2.00 & 0.40 & rc_H31859_at \\
\hline
\end{tabular}

unknown, 191 were expressed sequence tags (ESTs) and 119 were transcripts that represent a different region of one of the known genes. This left 1087 known genes (Tables S2 and S3).
As a first step in understanding functions of differentially expressed genes, we used the gene ontology (GO) classification of genes (http://www.godatabase.org/cgi-bin/ 
1074 A. G. Holt et al.

Table 2 Genes with greater than 2 fold increase in expression 21 days following deafness

\begin{tabular}{|c|c|c|c|c|}
\hline Gene Title & UniGene ID & Fold Change & q-value (\%) & Probe Set ID \\
\hline aquaporin 4 & Rn.90091 & 4.32 & 0.31 & U14007_at \\
\hline Unknown & Unknown & 4.26 & 0.54 & M13101cds_f_at \\
\hline LINE retrotransposable element 3 & Unknown & 4.01 & 0.54 & M13100cds\#6_f_at \\
\hline Unknown & Unknown & 4.00 & 0.54 & U83119_f_at \\
\hline Unknown & Unknown & 3.99 & 0.63 & X05472cds\#1_s_at \\
\hline Unknown & Unknown & 3.91 & 0.31 & X53581cds\#5_f_at \\
\hline Unknown & Unknown & 3.85 & 0.63 & X61295cds_s_at \\
\hline LINE retrotransposable element 3 & Unknown & 3.61 & 0.63 & M13100cds\#2_s_at \\
\hline LINE retrotransposable element 3 & Unknown & 3.54 & 1.17 & M13100cds\#4_f_at \\
\hline Unknown & Unknown & 3.51 & 0.63 & X07686cds_s_at \\
\hline $\begin{array}{l}\text { Similar to pinin; DNA segment, Chr 12, } \\
\text { ERATO Doi 512, expressed (LOC368070), mRNA }\end{array}$ & Rn.38987 & 3.20 & 0.31 & rc_Al639151_at \\
\hline visinin-like 1 & Rn.105934 & 3.03 & 0.31 & D10666_at \\
\hline synaptosomal-associated protein & Rn.107689 & 2.94 & 0.31 & AB003991_g_at \\
\hline LINE retrotransposable element 3 & Unknown & 2.92 & 0.31 & M13100cds\#3_f_at \\
\hline synaptosomal-associated protein & Rn.107689 & 2.86 & 0.31 & AB003992_s_at \\
\hline LINE retrotransposable element 3 & Unknown & 2.82 & 1.38 & M13100cds\#5_s_at \\
\hline Nclone10 mRNA & Rn.32307 & 2.75 & 0.31 & rc_Al071866_s_at \\
\hline Unknown & Unknown & 2.71 & 0.54 & X53581cds\#3_f_at \\
\hline $\begin{array}{l}\text { Similar to trinucleotide repeat containing 6; EDIE; } \\
\text { GW182 autoantigen (LOC308971), mRNA }\end{array}$ & Rn.6839 & 2.67 & 0.31 & rc_AA875500_at \\
\hline Similar to N-terminal aceyltransferase 1 (LOC310399), mRNA & Rn.12587 & 2.58 & 0.31 & rc_Al177404_at \\
\hline synaptosomal-associated protein & Rn.107689 & 2.52 & 0.31 & AB003991_at \\
\hline $\begin{array}{l}\text { Transcribed seq. with moderate similarity to protein } \\
\text { pdb:1LBG (E. coli) B Chain B, Lactose Operon Repressor } \\
\text { Bound To 21-Base Pair Symmetric Operator Dna, } \\
\text { Alpha Carbons Only }\end{array}$ & Rn.24387 & 2.49 & 0.31 & rc_AA891476_at \\
\hline microtubule-associated protein 2 & Rn.10484 & 2.37 & 1.38 & X17682_s_at \\
\hline LINE retrotransposable element 3 & Unknown & 2.32 & 0.63 & M13100cds\#1_g_at \\
\hline catalase & Rn.3001 & 2.27 & 0.31 & rc_AA926149_g_at \\
\hline myristoylated alanine rich protein kinase $C$ substrate & Rn.9560 & 2.24 & 0.31 & rc_AA955167_s_at \\
\hline Unknown & Unknown & 2.24 & 2.10 & X05472cds\#3_f_at \\
\hline Transcribed sequences & Rn.98479 & 2.22 & 0.31 & rc_AA874873_at \\
\hline $\begin{array}{l}\text { Rattus norvegicus focal adhesion kinase } \\
\text { (FAK) mRNA, alternative 5'UTR }\end{array}$ & Rn.806 & 2.22 & 0.31 & rc_AA874926_at \\
\hline $\begin{array}{l}\text { Similar to heterogeneous nuclear ribonucleoprotein } \\
\text { A2/B1 (LOC362361), mRNA }\end{array}$ & Rn.4057 & 2.20 & 0.31 & rc_AA799511_g_at \\
\hline microtubule-associated protein 2 & Rn.10484 & 2.20 & 2.08 & rc_Al228850_s_at \\
\hline Transcribed sequences & Rn.15385 & 2.19 & 0.31 & rc_Al639410_s_at \\
\hline microtubule-associated protein 2 & Rn.10484 & 2.19 & 1.64 & X53455cds_s_at \\
\hline gamma-aminobutyric acid A receptor, alpha 1 & Unknown & 2.18 & 0.54 & L08490cds_at \\
\hline Transcribed sequences & Rn.16596 & 2.17 & 0.31 & rc_Al638960_g_at \\
\hline Similar to RNA helicase A (LOC304859), mRNA & Rn.107359 & 2.17 & 0.31 & rc_Al639188_at \\
\hline dynamin 1-like & Rn. 10830 & 2.12 & 0.31 & AF020212_s_at \\
\hline LIC-2 dynein light intermediate chain $53 / 55$ & Rn.31981 & 2.11 & 0.31 & rc_AA891132_s_at \\
\hline chimerin (chimaerin) 1 & Rn.11166 & 2.11 & 0.31 & X67250_at \\
\hline Ac1054 mRNA, complete cds & Rn.3412 & 2.11 & 2.08 & rc_AA893212_at \\
\hline $\begin{array}{l}\text { solute carrier family } 24 \text { (sodium/potassium/calcium exchanger), } \\
\text { member } 2\end{array}$ & Rn.74242 & 2.11 & 0.31 & AF021923_at \\
\hline sodium channel, voltage-gated, type 2 , alpha 1 polypeptide & Rn.89192 & 2.11 & 0.31 & M22254_at \\
\hline $\begin{array}{l}\text { Similar to cAMP-dependent protein kinase, beta-2-catalytic } \\
\text { subunit (PKA C-beta-2) (LOC310986), mRNA }\end{array}$ & Rn.3502 & 2.10 & 5.03 & D10770_s_at \\
\hline casein kinase II beta subunit & Rn.11095 & 2.09 & 0.31 & L15619_at \\
\hline phospholipase $\mathrm{C}$, beta 1 & Rn.45523 & 2.09 & 0.31 & L14323_at \\
\hline
\end{tabular}


Table 2 Continued

\begin{tabular}{|c|c|c|c|c|}
\hline Gene Title & UniGene ID & Fold Change & q-value (\%) & Probe Set ID \\
\hline gap junction membrane channel protein alpha 1 & Rn.10346 & 2.08 & 3.49 & rc_Al029183_s_at \\
\hline glutamate receptor, ionotropic, 2 & Rn.91361 & 2.07 & 1.13 & M38061_at \\
\hline discs, large homolog 1 (Drosophila) & Rn.89331 & 2.07 & 0.31 & U14950_at \\
\hline matrin 3 & Rn.29774 & 2.06 & 0.31 & M63485_at \\
\hline $\begin{array}{l}\text { Similar to RNA-binding region (RNP1, RRM) containing 2; } \\
\text { splicing factor (CC1.3); coactivator of activating protein-1 } \\
\text { and estrogen receptors (LOC362251), mRNA }\end{array}$ & Rn.8555 & 2.06 & 0.31 & rc_AA800126_at \\
\hline Transcribed sequences & Rn.25117 & 2.06 & 0.31 & rc_AA799804_at \\
\hline Transcribed sequences & Rn.22663 & 2.05 & 0.63 & rc_H31859_at \\
\hline gamma-aminobutyric acid A receptor, gamma 2 & Unknown & 2.05 & 0.31 & L08497cds_at \\
\hline chimerin (chimaerin) 1 & Rn.11166 & 2.04 & 0.31 & rc_AA894317_s_at \\
\hline dynamin 1-like & Rn.10830 & 2.04 & 0.31 & AF019043_at \\
\hline solute carrier family 3 , member 1 & Rn.11196 & 2.02 & 3.49 & M80804_s_at \\
\hline Transcribed sequences & Rn.15956 & 2.00 & 0.31 & rc_Al639088_s_at \\
\hline
\end{tabular}

amigo/go.cgi), which assigns differentially expressed genes to groups based on molecular function and biological processes (Tables S2 and S3). Of these genes, over 300 in the 3-day deaf group and over 600 in the 21-day deaf group could not be classified, either because they were unknown genes or because they have not been formally assigned a molecular function or biological process based on GO terminology. Nonetheless, we were able to identify many neurotransmitter-related genes (Table 5 and Tables S2 and S3) that showed changes in expression and may contribute to auditory plasticity following deafening.

\section{Glutamate-related changes in expression}

GeneChip analysis identified many glutamate-related genes with significant and sustained increases in expression following deafening (Table 5). Of these excitatory neurotransmission related genes, five were further assessed with qRT-PCR and showed comparable changes (Fig. 1a). GluR 2 showed significant increases of 2.7-fold at 3 days, 2.9-fold at 21 days and 1.7-fold at 90 days. GluR 3 expression increased 3.3-fold and 3.0-fold at 3 and 21 days, respectively, and was still 2.7-fold higher than the control at 90 days. The expression of GluR K2 increased 2.5-fold at 3 days, 2.6-fold at 21 days, and was still 1.7-fold higher at 90 days. Similarly, glutaminase expression increased more than a 3-fold at both 3 and 21 days, and was still 2.6-fold higher at 90 days. Glutamine synthetase (glns) expression did not increase following deafening, with no significant change in glns expression at 3 days, and a modest decrease at 21 days. Similarly, qRT-PCR detected no change in expression $(<15 \%)$ at 3 and 21 days, with a somewhat greater $(24 \%)$ decrease at 90 days. None of the glutamate-related transcripts returned to normal levels of expression by 90 days (Table 5).

\section{GABA-A receptor subunits}

Increased gene expression was seen in the three major types $(\alpha, \beta$ and $\gamma$ ) of GABA-A receptor subunits using GeneChip analysis (Table 5). The $\beta 2, \beta 3, \gamma 1$ and $\gamma 2$ subunits of this inhibitory receptor were further investigated with qRT-PCR (Fig. 1b). GABA-A receptor $\beta 2$ expression increased more than 4-fold at 3 and 21 days, and was still 3-fold higher at 90 days following deafening. GABA-A $\beta 3$ and $\gamma 2$ mNRA levels were $>2$-fold higher at 3 and 21 days, with a return towards normal levels at 90 days. GABA-A receptor $\gamma 1$ subunit mRNA levels increased in the 3-day deaf group by GeneChip analysis, while the qRT-PCR data did not show an increase until 21 days and showed a return to near normal levels at 90 days. For GAD 65 there were small increases of 1.28-, 1.51- and 1.33-fold at 3, 21 and 90 days, respectively.

\section{Glycine receptor subunits}

GeneChip results for the $\alpha 2$ subunit of the glycine receptor showed a 1.6-fold increase in expression at 3 and 21 days (Table 5), while qRT-PCR detected little change (below $15 \%$ ) at 3 days, a 2.9-fold increase at 21 days, and a return to normal levels of expression by 90 days following deafening (Fig. 1c). GeneChip analysis detected no significant change in the expression of glycine receptors $\alpha 1$ or $\alpha 3$ (Table 5), and qRT-PCR detected little change (below 15\%) in glycine receptor subunit $\alpha 1$ at 3 days. By qRT-PCR, there was a slight increase of $30 \%$ in glycine $\alpha 1$ at 21 days and an almost 1.5-fold increase by 90 days (Fig. 1c and Table 5). Glycine receptor $\alpha 3$ had increased levels of expression (2.4-, 3.5- and 2.0-fold, respectively) at each of these three time points.

\section{Other genes assessed by qRT-PCR}

While GeneChip analysis did not detect a decrease in $\mathrm{TH}$ until 21 days (Table 5), qRT-PCR showed an approxi- 
Table 3 Genes with greater than 1.25 fold (25\%) decrease in expression 3 days following deafness

\begin{tabular}{|c|c|c|c|c|c|}
\hline Gene Title & UniGene ID & Fold Change & Deaf / Normal & q-value $(\%)$ & Probe Set ID \\
\hline early growth response 1 & Rn.9096 & -3.91 & 0.26 & 0.40 & AF023087_s_at \\
\hline Unknown & Unknown & -3.30 & 0.30 & 0.40 & U75397UTR\#1_s_at \\
\hline early growth response 1 & Rn.9096 & -3.23 & 0.31 & 0.40 & M18416_at \\
\hline VGF nerve growth factor inducible & Rn.9704 & -2.83 & 0.35 & 0.40 & M74223_at \\
\hline galectin-related inter-fiber protein & Rn.26894 & -2.22 & 0.45 & 0.40 & AF082160_at \\
\hline Similar to testican-2 protein (LOC361840), mRNA & Rn.66831 & -2.08 & 0.48 & 4.02 & rc_Al639294_at \\
\hline activity regulated cytoskeletal-associated protein & Rn.10086 & -1.82 & 0.55 & 0.40 & U19866_at \\
\hline preproenkephalin, related sequence & Rn.10015 & -1.80 & 0.55 & 0.40 & S49491_s_at \\
\hline Unknown & Unknown & -1.72 & 0.58 & 1.98 & rc_Al014135_g_at \\
\hline hydroxysteroid 11-beta dehydrogenase 1 & Rn.888 & -1.61 & 0.62 & 0.40 & rc_Al105448_at \\
\hline $\begin{array}{l}\text { Similar to Leucine-rich repeat-containing } 8 \\
\text { (LOC311846), mRNA }\end{array}$ & Rn.33512 & -1.56 & 0.64 & 2.89 & rc_AA875002_at \\
\hline Similar to carboxylesterase (LOC291863), mRNA & Rn.108790 & -1.51 & 0.66 & 5.46 & rc_AA800851_s_at \\
\hline Transcribed sequences & Rn.3130 & -1.48 & 0.68 & 1.98 & rc_AA874803_g_at \\
\hline Rgc32 protein & Rn.3504 & -1.46 & 0.68 & 0.93 & AF036548_g_at \\
\hline Rat mRNA for beta-tubulin T beta15 & Rn.37849 & -1.42 & 0.70 & 0.40 & X03369_s_at \\
\hline Unknown & Unknown & -1.41 & 0.71 & 1.98 & X03347cds_g_at \\
\hline protein tyrosine phosphatase, receptor type, $\mathrm{N}$ & Rn.11097 & -1.41 & 0.71 & 4.02 & D38222_s_at \\
\hline Max & Rn.4210 & -1.40 & 0.71 & 2.89 & D14448_s_at \\
\hline calcium/calmodulin-dependent protein kinase II alpha subunit & Rn.107499 & -1.40 & 0.71 & 4.02 & J02942_at \\
\hline phosphoglycerate mutase 1 & Rn.123549 & -1.40 & 0.72 & 5.46 & rc_Al169417_s_at \\
\hline chemokine (C-X3-C motif) ligand 1 & Rn.107266 & -1.38 & 0.73 & 0.40 & AF030358_g_at \\
\hline synaptic vesicle glycoprotein 2 a & Rn.11264 & -1.37 & 0.73 & 5.46 & L05435_at \\
\hline Unknown & Unknown & -1.37 & 0.73 & 1.39 & U17837UTR\#1_at \\
\hline protein kinase, cAMP-dependent, catalytic, alpha & Rn.103828 & -1.37 & 0.73 & 1.98 & X57986mRNA_s_at \\
\hline farensyl diphosphate synthase & Rn.2848 & -1.36 & 0.73 & 2.89 & rc_Al180442_at \\
\hline phosphodiesterase $4 \mathrm{~A}$ & Rn.91357 & -1.36 & 0.74 & 2.89 & M25348_s_at \\
\hline $\begin{array}{l}\text { ATP synthase, } \mathrm{H}+\text { transporting, mitochondrial F1 complex, } \\
\text { epsilon subunit }\end{array}$ & Rn.3454 & -1.36 & 0.74 & 2.89 & rc_Al171844_g_at \\
\hline Similar to 2700038E08Rik protein (LOC293725), mRNA & Rn.43300 & -1.36 & 0.74 & 4.02 & rc_AA860024_at \\
\hline pleckstrin homology, Sec7 and coiled/coil domains 3 & Rn.10673 & -1.33 & 0.75 & 2.89 & U83897_at \\
\hline $\begin{array}{l}\text { Similar to mitochondrial ribosomal protein S6 } \\
\text { (LOC288253), mRNA }\end{array}$ & Rn.41455 & -1.33 & 0.75 & 5.46 & rc_Al639387_at \\
\hline laminin receptor 1 (67kD, ribosomal protein SA) & Rn.999 & -1.29 & 0.77 & 5.46 & D25224_at \\
\hline proteasome (prosome, macropain) subunit, beta type 4 & Rn.6169 & -1.28 & 0.78 & 4.02 & L17127_g_at \\
\hline Unknown & Unknown & -1.28 & 0.78 & 4.02 & D13623_g_at \\
\hline Transcribed sequences & Rn.6620 & -1.27 & 0.79 & 1.98 & rc_AA800693_g_at \\
\hline
\end{tabular}

mately $50 \%$ decrease in $\mathrm{TH}$ expression at 3, 21 and 90 days following deafness (Fig. 1d). Prepronociceptin (PNOC) and pre-proenkephalin (PENK) expression levels also decreased at these three times. Serotonin receptor $5 \mathrm{~B}$ (5-HT 5B) decreased approximately $20 \%$ at 3 and 21 days following deafness, but returned to normal by 90 days. The activity- and neurotransmitter-induced gene, ANIA4, had comparable slight increases in expression at 3 days with both GeneChip analysis and qRT-PCR. There was, however, a difference at 21 days, where an increase was seen in the GeneChip analysis, while there was a large decrease in expression (80-90\%) at 21 and 90 days detected by qRT-PCR.

\section{Immunocytochemical distribution of differentially} expressed genes in the IC

Immunocytochemistry was used to examine the distribution of five proteins in the IC; GABA $\beta 3$, GABA $\gamma 2$, glutamate receptor $2 / 3$ (Fig. 2), TH, and PPENK (Fig. 3). These immunolabeling studies identified the neurons and cellular elements containing products ultimately produced by the gene. We also examined whether changes in expression following deafness could be translated into changes in production and/or localization and whether the changes were sufficient to be appreciated in a qualitative appraisal. Comparing the 3- and 21-day deafened group with the normal group, there were not sufficient differences in the 
Table 4 Genes with greater than 1.25 fold (25\%) decrease in expression 21 days following deafness

\begin{tabular}{|c|c|c|c|c|c|}
\hline Gene Title & UniGene ID & Fold Change & Deaf / Normal & q-value (\%) & Probe Set ID \\
\hline VGF nerve growth factor inducible & Rn.9704 & -2.72 & 0.37 & 0.31 & M74223_at \\
\hline early growth response 1 & Rn.9096 & -2.18 & 0.46 & 3.49 & AF023087_s_at \\
\hline Unknown & Unknown & -2.02 & 0.49 & 5.03 & U75397UTR\#1_s_at \\
\hline serum/glucocorticoid regulated kinase & Rn.4636 & -1.98 & 0.51 & 5.03 & L01624_at \\
\hline protein tyrosine phosphatase, non-receptor type 16 & Rn.98260 & -1.83 & 0.55 & 2.08 & S74351_s_at \\
\hline protein tyrosine phosphatase, non-receptor type 16 & Rn.98260 & -1.82 & 0.55 & 3.49 & S81478_s_at \\
\hline preproenkephalin, related sequence & Rn.10015 & -1.82 & 0.55 & 0.31 & S49491_s_at \\
\hline activity regulated cytoskeletal-associated protein & Rn.10086 & -1.79 & 0.56 & 0.31 & U19866_at \\
\hline Similar to carboxylesterase (LOC291863), mRNA & Rn.108790 & -1.77 & 0.56 & 0.54 & rc_AA800851_s_at \\
\hline ATP-binding cassette, subfamily C (CFTR/MRP), member 8 & Rn.11187 & -1.74 & 0.58 & 3.49 & rc_AA799786_s_at \\
\hline $\begin{array}{l}\text { nuclear factor of kappa light chain gene } \\
\text { enhancer in B-cells inhibitor, alpha }\end{array}$ & Rn.12550 & -1.65 & 0.61 & 1.64 & X63594cds_g_at \\
\hline neuronal $\mathrm{d} 4$ domain family member & Rn.42906 & -1.61 & 0.62 & 4.54 & X66022mRNA\#1_s_at \\
\hline immediate early gene transcription factor NGFI-B & Rn.10000 & -1.61 & 0.62 & 3.49 & U17254_g_at \\
\hline synaptic vesicle glycoprotein 2 a & Rn.11264 & -1.60 & 0.63 & 2.10 & L05435_at \\
\hline Similar to talin (LOC313494), mRNA & Rn.7715 & -1.57 & 0.64 & 5.03 & rc_AA800962_at \\
\hline protein tyrosine phosphatase, non-receptor type 16 & Rn.98260 & -1.55 & 0.64 & 1.13 & U02553cds_s_at \\
\hline Similar to RIKEN cDNA $1110020 \mathrm{C} 13$ (LOC363004), mRNA & Rn.2990 & -1.53 & 0.65 & 3.49 & rc_AA800199_at \\
\hline $\begin{array}{l}\text { Similar to transformation/transcription } \\
\text { domain-associated protein (LOC288471), mRNA }\end{array}$ & Rn.92036 & -1.52 & 0.66 & 2.34 & rc_AA800513_at \\
\hline $\begin{array}{l}\text { nuclear factor of kappa light chain gene } \\
\text { enhancer in B-cells inhibitor, alpha }\end{array}$ & Rn.12550 & -1.52 & 0.66 & 1.64 & X63594cds_at \\
\hline Similar to T-cell differentiation antigen (LOC311635), mRNA & Rn.25180 & -1.51 & 0.66 & 2.69 & rc_AA799761_at \\
\hline RT1 class II, locus Bb & Rn.20089 & -1.49 & 0.67 & 4.02 & M36151cds_I_at \\
\hline discs, large homolog 4 (Drosophila) & Rn.9765 & -1.49 & 0.67 & 0.31 & M96853_at \\
\hline Unknown & Unknown & -1.45 & 0.69 & 0.31 & X03347cds_g_at \\
\hline myosin heavy chain 11 & Rn.94969 & -1.45 & 0.69 & 5.03 & X16261_i_at \\
\hline peroxiredoxin 6 & Rn.42 & -1.45 & 0.69 & 2.08 & AF014009_at \\
\hline macrophage galactose $\mathrm{N}$-acetyl-galactosamine specific lectin & Rn.779 & -1.44 & 0.69 & 2.89 & J05495_at \\
\hline protein tyrosine phosphatase, receptor type, $\mathrm{N}$ & Rn.11097 & -1.44 & 0.70 & 3.49 & D38222_s_at \\
\hline Transcribed sequences & Rn.4292 & -1.43 & 0.70 & 3.49 & rc_AA799347_at \\
\hline Transcribed sequences & Rn.6676 & -1.43 & 0.70 & 5.03 & rc_AA800971_at \\
\hline Rat mRNA for beta-tubulin $\mathrm{T}$ beta15 & Rn.37849 & -1.42 & 0.70 & 1.38 & X03369_s_at \\
\hline Similar to RIKEN cDNA 4930415K17 (LOC291670), mRNA & Rn.105695 & -1.41 & 0.71 & 2.08 & rc_H33001_at \\
\hline $\begin{array}{l}\text { Similar to DNA segment, Chr 19, ERATO Doi 386, } \\
\text { expressed (LOC361064), mRNA }\end{array}$ & Rn.30496 & -1.41 & 0.71 & 4.54 & rc_AA892753_s_at \\
\hline Transcribed sequences & Rn.6620 & -1.39 & 0.72 & 1.13 & rc_AA800693_g_at \\
\hline hydroxysteroid 11-beta dehydrogenase 1 & Rn.888 & -1.39 & 0.72 & 1.13 & rc_Al105448_at \\
\hline disks large-associated protein 4 & Rn.11279 & -1.38 & 0.72 & 2.89 & U67140_g_at \\
\hline calreticulin & Rn.974 & -1.38 & 0.72 & 2.89 & D78308_at \\
\hline solute carrier family 2 ,member 1 & Rn.3205 & -1.38 & 0.72 & 1.17 & S68135_s_at \\
\hline calcium/calmodulin-dependent protein kinase II alpha subunit & Rn.107499 & -1.38 & 0.72 & 2.08 & J02942_at \\
\hline $\begin{array}{l}\text { Similar to } 26 \mathrm{~S} \text { proteasome non-ATPase regulatory subunit } 11 \\
\text { (26S proteasome regulatory subunit S9) (26S proteasome } \\
\text { regulatory subunit p44.5) (LOC303353), mRNA }\end{array}$ & Rn.11861 & -1.38 & 0.72 & 1.17 & rc_AA892831_s_at \\
\hline Rgc32 protein & Rn.3504 & -1.38 & 0.73 & 2.69 & AF036548_at \\
\hline Jun-B oncogene & Rn.15806 & -1.38 & 0.73 & 2.34 & rc_AA891041_at \\
\hline endothelin converting enzyme-like 1 & Rn.45803 & -1.37 & 0.73 & 1.17 & Y16188_at \\
\hline Transcribed sequences & Rn.3130 & -1.37 & 0.73 & 1.17 & rc_AA874803_g_at \\
\hline c-fos oncogene & Rn. 103750 & -1.37 & 0.73 & 1.64 & X06769cds_at \\
\hline Similar to cDNA sequence BC019776 (LOC316842), mRNA & Rn.64557 & -1.37 & 0.73 & 2.10 & rc_Al639012_at \\
\hline $\begin{array}{l}\text { Similar to Tubulin alpha-4 chain (Alpha-tubulin 4) } \\
\text { (LOC316531), mRNA }\end{array}$ & Rn.92961 & -1.36 & 0.73 & 4.54 & rc_AA800948_at \\
\hline Unknown & Unknown & -1.36 & 0.73 & 1.17 & S82649_s_at \\
\hline
\end{tabular}


Table 4 Continued

\begin{tabular}{|c|c|c|c|c|c|}
\hline Gene Title & UniGene ID & Fold Change & Deaf / Normal & q-value $(\%)$ & Probe Set ID \\
\hline Similar to guanylate kinase (LOC303179), mRNA & Rn.36522 & -1.36 & 0.73 & 0.31 & rc_AA800291_at \\
\hline Unknown & Unknown & -1.36 & 0.73 & 0.31 & U17837UTR\#1_at \\
\hline farensyl diphosphate synthase & Rn.2848 & -1.36 & 0.73 & 1.38 & rc_Al180442_at \\
\hline nerve growth factor, gamma & Rn.11331 & -1.36 & 0.74 & 5.03 & M19647_i_at \\
\hline Unknown & Unknown & -1.36 & 0.74 & 4.54 & AFFX-BioB-5_at \\
\hline $\begin{array}{l}\text { ATP synthase, } \mathrm{H}+\text { transporting, mitochondrial } \\
\text { F1 complex, delta subunit }\end{array}$ & Rn.3879 & -1.35 & 0.74 & 5.03 & U00926_at \\
\hline $\begin{array}{l}\text { ATP synthase, } \mathrm{H}+\text { transporting, mitochondrial } \\
\text { F1 complex, epsilon subunit }\end{array}$ & Rn.3454 & -1.35 & 0.74 & 1.64 & rc_Al171844_g_at \\
\hline mast cell protease 4 & Rn.10698 & -1.34 & 0.74 & 2.10 & U67907_f_at \\
\hline Similar to R31449_3 (LOC314641), mRNA & Rn.2928 & -1.34 & 0.74 & 1.17 & rc_AA799473_at \\
\hline $\begin{array}{l}\text { calcium/calmodulin-dependent protein kinase } \\
\text { (CaM kinase) II gamma }\end{array}$ & Rn.10961 & -1.34 & 0.75 & 4.02 & U73503_at \\
\hline $\begin{array}{l}\text { Transcribed sequence with weak similarity to protein } \\
\text { ref:NP_075568.1 (H.sapiens) hypothetical } \\
\text { protein FLJ20989 [Homo sapiens] }\end{array}$ & Rn.2859 & -1.34 & 0.75 & 2.89 & rc_AA891551_at \\
\hline Similar to cation-transporting atpase (LOC290673), mRNA & Rn.3697 & -1.33 & 0.75 & 1.64 & rc_AA893621_at \\
\hline $\begin{array}{l}\text { Similar to } 17,000 \text { dalton myosin light chain } \\
\text { (LOC362816), mRNA }\end{array}$ & Rn.969 & -1.33 & 0.75 & 3.49 & rc_AA875523_i_at \\
\hline apolipoprotein A-I & Rn.10308 & -1.33 & 0.75 & 4.54 & J02597cds_s_at \\
\hline tumor-associated protein 1 & Rn.32261 & -1.32 & 0.76 & 2.89 & AB015432_s_at \\
\hline $\begin{array}{l}\text { Similar to DGCR6 protein (DiGeorge syndrome critical } \\
\text { region } 6 \text { homolog) (LOC303794), mRNA }\end{array}$ & Rn.22467 & -1.32 & 0.76 & 1.38 & rc_AA799732_at \\
\hline Similar to 2700038E08Rik protein (LOC293725), mRNA & $\operatorname{Rn} .43300$ & -1.32 & 0.76 & 2.10 & rc_AA860024_at \\
\hline ribosomal protein L14 & Rn.108039 & -1.32 & 0.76 & 3.49 & X94242_at \\
\hline $\begin{array}{l}\text { Transcribed sequence with strong similarity to protein } \\
\text { ref:NP_062269.1 (M.musculus) cysteine and histidine rich 1; } \\
\text { cysteine and histidine-rich cytoplasmic protein [Mus musculus] }\end{array}$ & Rn.8316 & -1.32 & 0.76 & 5.03 & rc_AA891802_at \\
\hline prepronociceptin & Rn.87935 & -1.32 & 0.76 & 0.63 & S79730_s_at \\
\hline Similar to KIAA1064 protein (LOC308385), mRNA & Rn.98823 & -1.32 & 0.76 & 0.31 & rc_AA893980_at \\
\hline methylenetetrahydrofolate reductase & Rn.10494 & -1.31 & 0.76 & 5.03 & U57049_at \\
\hline Rgc32 protein & Rn.3504 & -1.31 & 0.76 & 3.49 & AF036548_g_at \\
\hline Unknown & Unknown & -1.31 & 0.76 & 5.03 & L48618_at \\
\hline CDNA clone MGC:72845 IMAGE:6917939, complete cds & Rn.119365 & -1.31 & 0.76 & 4.54 & rc_Al103236_at \\
\hline $\begin{array}{l}\text { Transcribed sequence with strong similarity to protein } \\
\text { ref:NP_037465.1 (H.sapiens) EH domain-binding } \\
\text { mitotic phosphoprotein [Homo sapiens] }\end{array}$ & Rn.14814 & -1.30 & 0.77 & 1.17 & rc_AA893612_at \\
\hline von Hippel-Lindau syndrome homolog & Rn.11059 & -1.30 & 0.77 & 0.63 & U14746_at \\
\hline $\begin{array}{l}\text { ATP synthase, } \mathrm{H}+\text { transporting, mitochondrial } \\
\text { F1 complex, epsilon subunit }\end{array}$ & Rn.3454 & -1.30 & 0.77 & 5.03 & rc_Al171844_at \\
\hline solute carrier family 12, member 2 & Rn.11523 & -1.30 & 0.77 & 5.03 & AF086758_at \\
\hline Similar to tumor-rejection antigen SART3 (LOC304582), mRNA & Rn.101480 & -1.30 & 0.77 & 0.31 & rc_Al639476_s_at \\
\hline phosphoglycerate mutase 1 & Rn.123549 & -1.30 & 0.77 & 4.02 & rc_Al169417_s_at \\
\hline $\begin{array}{l}\text { Transcribed sequence with moderate similarity to protein } \\
\text { ref:NP_037529.1 (H.sapiens) over-expressed breast } \\
\text { tumor protein [Homo sapiens] }\end{array}$ & Rn.1327 & -1.30 & 0.77 & 5.03 & rc_AA891796_at \\
\hline Similar to hypothetical protein MGC6696 (LOC293719), mRNA & Rn.2847 & -1.29 & 0.77 & 0.63 & rc_AA800039_s_at \\
\hline $\operatorname{Max}$ & Rn.4210 & -1.29 & 0.77 & 2.10 & D14448_s_at \\
\hline Transcribed sequence & Rn.114062 & -1.29 & 0.77 & 2.34 & rc_AA892154_g_at \\
\hline lactate dehydrogenase $\mathrm{A}$ & Rn.107896 & -1.29 & 0.77 & 2.34 & M54926_at \\
\hline $\begin{array}{l}\text { ATP synthase, } \mathrm{H}+\text { transporting, mitochondrial } \\
\text { F1 complex, delta subunit }\end{array}$ & Rn.3879 & -1.29 & 0.77 & 5.03 & U00926_g_at \\
\hline ribosomal protein L18 & Rn.484 & -1.29 & 0.78 & 4.02 & M20156_at \\
\hline phosphodiesterase 4A & Rn.91357 & -1.29 & 0.78 & 2.10 & M26715_at \\
\hline
\end{tabular}


Table 4 Continued

\begin{tabular}{|c|c|c|c|c|c|}
\hline Gene Title & UniGene ID & Fold Change & Deaf / Normal & q-value $(\%)$ & Probe Set ID \\
\hline solute carrier family 2 ,member 1 & Rn.3205 & -1.28 & 0.78 & 1.64 & M13979_at \\
\hline Transcribed sequences & Rn.98517 & -1.28 & 0.78 & 2.34 & rc_AA800719_at \\
\hline ATPase, vacuolar, $14 \mathrm{kD}$ & Rn.6167 & -1.28 & 0.78 & 4.54 & U43175_at \\
\hline $\begin{array}{l}\text { potassium voltage-gated channel, KQT-like subfamily, } \\
\text { member } 1\end{array}$ & Rn.9779 & -1.28 & 0.78 & 1.46 & U92655_at \\
\hline $\begin{array}{l}\text { Similar to eukaryotic translation initiation factor } 3 \text { subunit } 7 \text {; } \\
\text { eukaryotic translation initiation factor } 3 \text {, subunit } \\
7 \text { (zeta, 66/67kD); translation initiation factor elF3 p66 } \\
\text { subunit (LOC362952), mRNA }\end{array}$ & Rn.3463 & -1.28 & 0.78 & 2.89 & rc_AA891553_at \\
\hline myosin heavy chain, polypeptide 7 & Rn.48663 & -1.27 & 0.78 & 2.10 & X15939_f_at \\
\hline insulin 1 & Rn.962 & -1.27 & 0.79 & 2.34 & E00001cds_f_at \\
\hline major intrinsic protein of eye lens fiber & Rn.23532 & -1.27 & 0.79 & 4.54 & X53052cds_g_at \\
\hline peroxiredoxin 6 & Rn.42 & -1.27 & 0.79 & 5.03 & rc_AA892041_at \\
\hline nucleoside diphosphate kinase & Rn.927 & -1.27 & 0.79 & 5.03 & M91597_s_at \\
\hline Transcribed sequences & Rn.13477 & -1.27 & 0.79 & 2.69 & rc_AA893124_at \\
\hline c-fos oncogene & Rn. 103750 & -1.27 & 0.79 & 2.89 & X06769cds_g_at \\
\hline laminin receptor 1 (67kD, ribosomal protein $\mathrm{SA})$ & Rn.999 & -1.26 & 0.79 & 1.64 & D25224_at \\
\hline proline-rich protein 15 & Unknown & -1.26 & 0.79 & 2.34 & M83567_s_at \\
\hline isovaleryl coenzyme A dehydrogenase & Rn.147 & -1.26 & 0.79 & 2.69 & rc_Al102838_s_at \\
\hline Tonin & Rn.9882 & -1.26 & 0.79 & 4.02 & M26534_i_at \\
\hline $\begin{array}{l}\text { Similar to non-receptor protein tyrosine kinase Ack } \\
\text { (LOC303882), mRNA }\end{array}$ & Rn.98335 & -1.26 & 0.79 & 2.69 & rc_H31144_g_at \\
\hline methyl CpG binding protein 2 & Rn.9680 & -1.26 & 0.79 & 2.69 & M94064_at \\
\hline
\end{tabular}

immunolabeling to be striking for any of the antibodies used, either in the number of labeled elements and/or the intensity of labeling. However, for many of these proteins there were large enough changes in immunolabeling in the 90-day deaf group compared with labeling in the normal hearing control group (Figs 2 and 3 ) to be obviously different in a qualitative appraisal.

\section{GABA receptor subunit immunolabeling}

Numerous neurons were immunolabeled for GABA $\beta 3$ throughout the three regions of the IC of normal hearing animals with the labeling having a punctate appearance and many prominent neurons located throughout the nucleus with the fewest labeled neurons observed in the central nucleus (Fig. 2a). In deafened animals the neuropil labelling was comparable with modestly increased levels of label in 3-day and 21-day deaf groups, but the 90-day deaf group was strikingly increased compared with the 3-day and 21-day deaf groups and controls, with the label for the subunit outlining many neurons, including several primary dendrites (Fig. 2b).

Neurons immunostained for the $\gamma 2$ subunit of the GABA-A receptor were also distributed throughout the $\mathrm{IC}$, with a punctate label filling the somata of the cells. A large number of these neurons were found in the central nucleus (Fig. 2c). In animals deafened for 3 days, neither the distribution nor the number of neurons immunostained for the $\gamma 2$ subunit appeared to change, nor did the intensity of labeling. However, in the 21- day and 90-day deafened groups the number of labeled cells increased, particularly in the central nucleus of the IC (Fig. 2d) with more primary dendrites being labeled.

\section{Glutamate receptor subunit immunolabeling}

An antibody that immunolabels glutamate receptors containing both the 2 and 3 subunits (GluR 2/3) was used. GluR 2/3 immunolabel filled cell bodies and the labeling was found primarily in small to medium-sized cells $(\leq 20 \mu \mathrm{m})$ scattered throughout the central nucleus of the IC. No obvious differences in labeling were found in the 3- and 21-day deaf groups compared with that of the control group, with a modest increase in the 90-day deaf group in the number of labeled cells. Immunolabeled neurons formed clusters or patches within the central nucleus of the IC (Fig. 2e) that become more prominent in the 90-day deaf group (Fig. 2f).

\section{Neuropeptide immunolabeling}

In normal animals there were very few PENK labeled cell bodies observed in the IC. However, there were labeled fibers and puncta throughout the nucleus, with a higher concentration of label in the dorsal cortex (Fig. 3a). While there was no apparent diminution of label in the 3- and 21-day deaf groups when compared with the control group, in the 90-day deaf group there was a general decrease in labeling of fibers and puncta in deafened animals (Fig. 3b) with fairly intense labeling maintained in the dorsal cortex. 
Table 5 Comparison of gene expression 3 and 21 days after deafening: GeneChip vs qRT-PCR data

\begin{tabular}{|c|c|c|c|c|c|c|}
\hline \multirow[b]{2}{*}{ Gene Name } & \multirow[b]{2}{*}{ unigene id } & \multicolumn{2}{|c|}{3 day vs. control } & \multicolumn{2}{|c|}{21 day vs. control } & \multirow{2}{*}{$\frac{90 \text { day vs. control }}{\text { qRT-PCR }^{\mathrm{b}}}$} \\
\hline & & GeneChip $^{a}$ & qRT-PCR ${ }^{b}$ & GeneChip $^{a}$ & qRT-PCR ${ }^{b}$ & \\
\hline \multicolumn{7}{|l|}{ GLUTAMATE RELATED GENES } \\
\hline glutamate receptor, ionotropic, $2^{d}$ & Rn.91361 & 1.70 & 2.67 & 1.61 & 2.87 & 1.70 \\
\hline glutamate receptor, ionotropic, $2^{d}$ & Rn.91361 & 1.53 & 2.67 & 1.23 & 2.87 & 1.70 \\
\hline glutamate receptor, ionotropic, 3 & Rn.74049 & 1.25 & 3.34 & 1.07 & 2.95 & 2.73 \\
\hline glutamate receptor, ionotropic, kainate 2 & Rn.87696 & 1.32 & 2.47 & 1.23 & 2.61 & 1.67 \\
\hline glutaminase (gls) & Rn.5762 & 1.52 & 3.50 & 1.44 & 3.13 & 2.62 \\
\hline glutamine synthetase 1 (glns) & Rn.2204 & no change & - & -1.14 & - & -1.32 \\
\hline \multicolumn{7}{|l|}{ GABA RELATED GENES } \\
\hline GABA A receptor b 2 & Rn.48880 & 1.61 & 4.42 & no change & 4.26 & 3.35 \\
\hline GABA A receptor b 3 & Rn.53967 & 1.48 & 3.07 & no change & 2.81 & 2.62 \\
\hline GABA A receptor g 1 & Rn.10366 & 1.33 & - & 1.41 & 1.48 & - \\
\hline GABA A receptor g 3 & Rn.103894 & 1.88 & 2.15 & 2.05 & 2.37 & 1.70 \\
\hline glutamate decarboxylase 2 (GAD 65) & Rn.29951 & 1.41 & 1.28 & 1.52 & 1.51 & 1.33 \\
\hline \multicolumn{7}{|l|}{ GLYCINE RELATED GENES } \\
\hline glycine a 1 & Rn.10109 & no change & - & no change & 1.30 & 1.39 \\
\hline glycine a 2 & Rn.10379 & 1.56 & - & 1.57 & 2.86 & - \\
\hline glycine a 3 & Rn.10038 & no change & 2.37 & no change & 3.54 & 2.50 \\
\hline \multicolumn{7}{|l|}{ OTHER GENES } \\
\hline 5-hydroxytryptamine (serotonin) receptor 5B & Rn.10572 & no change & -1.22 & -1.17 & -1.19 & - \\
\hline 5-hydroxytryptamine (serotonin) receptor $2 \mathrm{C}^{\mathrm{d}}$ & Rn.9935 & 1.39 & 2.19 & 1.65 & 2.18 & 2.30 \\
\hline 5-hydroxytryptamine (serotonin) receptor $2 \mathrm{C}^{\mathrm{d}}$ & Rn.9935 & no change & 2.19 & 1.86 & 2.18 & 2.30 \\
\hline preproenkephalin, related sequence & Rn.10015 & -1.82 & - & -1.82 & -1.22 & -1.25 \\
\hline prepronociceptin (neuropeptide nociceptin) (N23K) & Rn.87935 & no change & -1.69 & -1.32 & -2.27 & -1.40 \\
\hline $\begin{array}{l}\text { activity and neurotransmitter-induced early } \\
\text { gene protein } 4 \text { (ania-4) }\end{array}$ & Rn.80575 & 1.28 & 1.18 & 1.33 & -7.14 & -7.89 \\
\hline tyrosine hydroxylase & Rn.11082 & no change & -2.33 & -1.18 & -2.04 & -2.28 \\
\hline
\end{tabular}

\footnotetext{
a. Change in intensity, expressed as fold change

b. Expressed as fold change $\left(2^{|\Delta \Delta \mathrm{Ct}|}\right)$, with the decreased expression indicated by a minus sign.

Note: The exponent in the fold change calculation is expressed as an absolute value.

c. No GeneChips run for this group

d. Same gene but different probe set on GeneChip

- Less that $15 \%$ change
}

Tyrosine hydroxylase immunolabeled neurons were found throughout the IC of normal animals. However, there were so many intensely immunolabeled fibers and puncta observed throughout the IC, immunolabeling of cells was obscured. Specifically, bundles of immunolabeled fibers were found coursing through the dorsal cortex (Fig. 3c). While there was only a slight decrease in labeling in the 3-day deaf group, there were dramatic reductions in labeled cells and fibers in the 21-day and 90-day deaf groups throughout the IC when comparing deafened (Fig. 3d) and normal hearing animals (Fig. 3c).

\section{Discussion}

GeneChip analysis using SAM identified large numbers of genes as showing significant differential expression across groups in the rat IC 3 and 21 days following bilateral cochlear ablation. The level of expression and the magnitude of change are also often considered when assigning functional relevance to an identified change in expression. We have chosen not to add these constraints to our assessment as, even small changes, when they appear consistently (as shown by a test of significance), can have functional implications. Information on magnitude of changes in gene expression, however, is reported in Table 5.

Activity-dependent changes in the expression of several genes shown to be differentially expressed, including, tyrosine kinase, JUN, EGR1, calbindin, MAP and protein kinase $\mathrm{C}$ (PKC), have previously been demonstrated in the auditory brainstem (Garcia et al. 2000; Illing 2001; Kotak and Sanes 2002; Michler and Illing 2003; Zhang et al. 2004). Increased neuronal activity is known to activate immediate early genes C-FOS, JUN and EGR1 (Akins et al. 1996), which are often used as markers of neuronal 
(a)

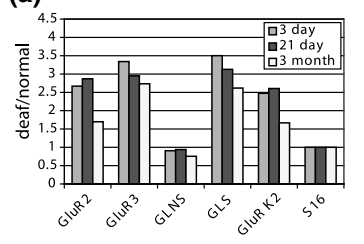

(b)

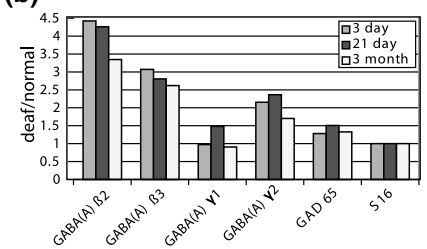

(c)

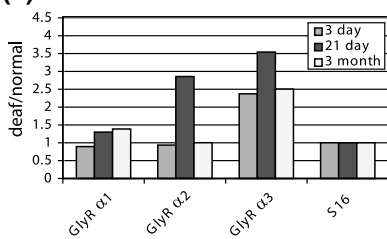

(d)

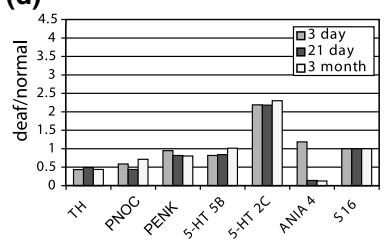

Fig. 1 Neurotransmitter-related genes are differentially expressed following deafferentation. Bar graphs of qRT-PCR showing differential gene expression of glutamate-related (a), GABA-related (b), glycinerelated (c) and neuropeptide-related (d) genes following bilateral cochlear ablation. Data are expressed as a ratio, gene expression from deafened animals divided by gene expression from normal animals. Grey bars represent gene expression from 3-day deaf animals, black bars represent expression levels of 21-day deaf groups and white bars represent expression from 3-month deaf animals. Only two of the 19 genes tested (GlyR $\alpha 2$ and 5-HT 5B) had returned to normal levels of expression by 90 days.

activity. As expected, JUN and EGR1 showed large decreases in expression following deafening. The present study also demonstrated changes in the levels of mRNA for various neurotransmission-related genes that have been studied previously. Our results are consistent with and extend previous analyses.

\section{Glutamate receptor modulation}

There are several receptor subtypes responsible for the binding of excitatory neurotransmitter. In our study, the level of expression for two AMPA receptor subunits (GlurR 2 and GluR 3) and one kainate receptor subunit (GluR K2) were significantly higher at all times following deafening. The GluR 2-GluR 3 receptor combination is believed to be continuously delivered to the synapse in a non-activity-dependent manner, while the GluR1-GluR2 receptor combination, as well as those containing GluR 4, are delivered to the synapse in an activity-dependent manner (Malinow et al. 2000; Passafaro et al. 2001; Shi et al. 2001).

Genes for ras, CamK2, mitogen-activated protein kinase, and protein kinase $\mathrm{A}$, each implicated in the insertion of AMPA receptors into the synapse, showed increased expression. Gene expression for PKC and rap, implicated in the removal of AMPA receptors from the synapse, also increased. This may indicate a high rate of turn-over/delivery of the constitutive receptor (GluR2-GluR3) and an increase in the insertion of the more plastic receptor combination containing the GluR 1 and GluR 2 receptor subunits. We also found decreased expression of glutamine synthetase, a key enzyme in the recycling of glutamate and increased expression of glutaminase, an enzyme that catalyzes the reaction of glutamine to glutamate.

\section{GABA-related genes}

The current study demonstrated sustained increases in the expression in three GABA-A receptor subunit types, with high levels of expression for $\beta 2, \beta 3$ and $\gamma 2$ even at 90 days following bilateral cochlear ablation. This suggests compensatory postsynaptic mechanisms that increase expression of these inhibitory receptors at the synapse when presynaptic transmitter function decreases.

The GABA-A $\gamma 2$ receptor subunit plays a role in transport and placement of the receptor complexes (Kittler and Moss 2003; Schweizer et al. 2003). We found increased expression of the GABA-A $\gamma 2$ subunit along with differential expression of other genes associated with placement of functional receptors into the synapse, such as clathrin (Lee et al. 2002; Blanpied et al. 2003), dynamin (Okamoto et al. 2001; Bobanovic et al. 2002; Carvelli et al. 2002), and adaptor protein-2 (Kittler et al. 2002). There was also increased expression of cAMP-dependent protein kinase, PKC, and tyrosine kinase which modulate GABA receptors through phosphorylation of $\beta$ and $\gamma$ subunits. Interestingly, we found increased expression of $\beta 3$ subunits where phosphorylation leads to increased activity of the receptor, perhaps leading to more 'sensitive' GABA-A receptors following deafness.

\section{Glycine receptor modulation}

Studies (Kungel et al. 1997; Piechotta et al. 2001) have found low levels of expression of the 'immature' glycine receptor $\alpha 2$ subunit in post-natal animals. We found increased expression of the inhibitory receptor's $\alpha 2$ subunit following deafness. The $\alpha 2$ subunit may confer such functional properties as a mean increase in channel open time (Takahashi et al. 1992; Mangin et al. 2002), an increase of the desensitization constant, and an increase in the duration of the postsynaptic current. The function of glycine receptors has been shown to be enhanced by phosphorylation of $\alpha$ subunits by cAMP-dependent protein kinase, calciumdependent calmodulin kinase II (CamK), PKC (Legendre 2001 ) and the glycine $\beta$ subunit by tyrosine kinase (Caraiscos et al. 2002), all of which increased in expression in the current study with the exception of CamK2a and CamK2g which decreased in expression.

\section{Other neurotransmission-related genes}

There was decreased $\mathrm{TH}$ in the IC following deafness, which correlates well with recent findings by Niu et al. (2004) that acoustic trauma decreases $\mathrm{TH}$ in the lateral olivocochlear system. Nociceptin and enkephalin also showed decreased 


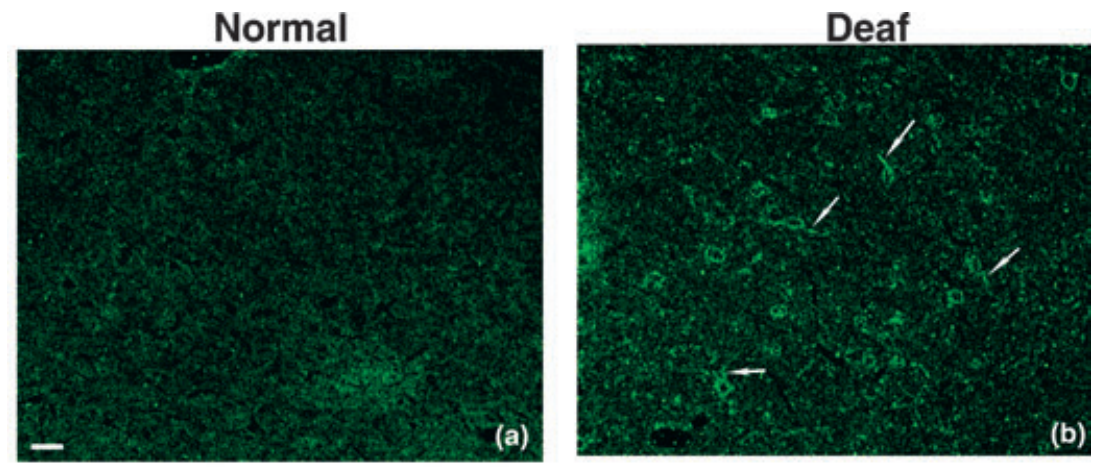

GABA-A $\beta 3$
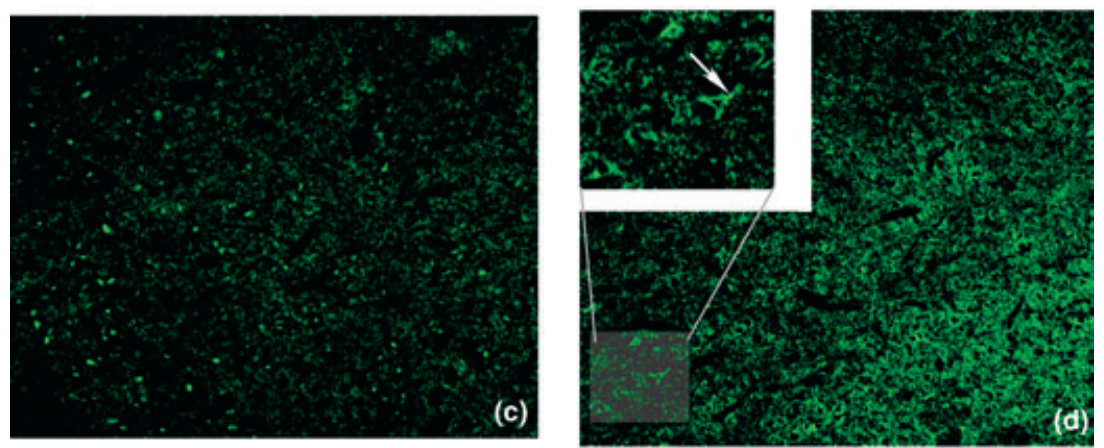

GABA-A $\gamma 2$
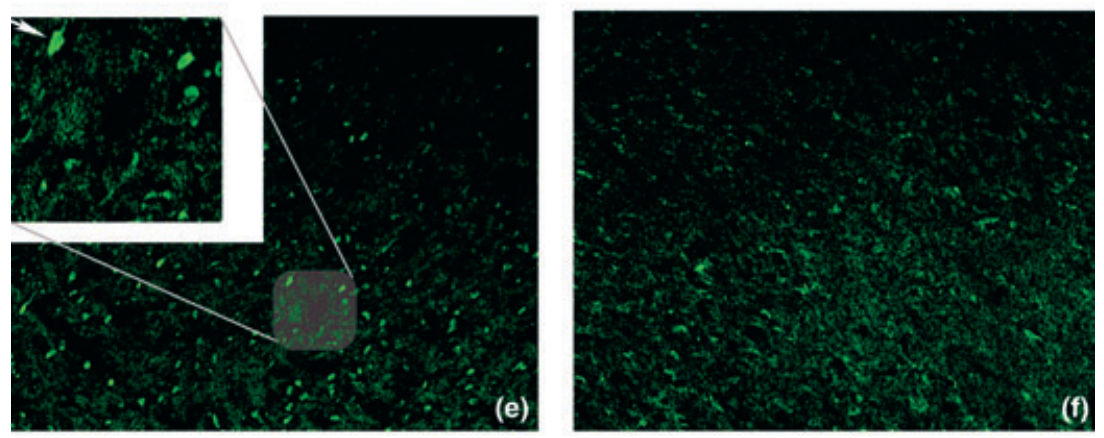

GluR 2/3
Fig. 2 Changes in immunoreactivity for GABA (a-d) and glutamate (e, f) receptor subunits in the central nucleus of the inferior colliculus. Photomicrographs of subunits for GABA-A $\beta 3$ (a, b) GABA-A $\gamma 2$ (c, d) and GluR 2/3 (e, f) receptor immunoreactive cells and/or fibers. Immunoreactivity from animals deafened for 90 days ( $b, d, f)$ is more robust when compared with labeling from normal animals (a, c, d). Following deafness, the labeling for GABA-A $\beta 3$ and GABA-A $\gamma 2$ is found in more primary dendrites (arrows in $b$ and $d$ ) when compared with labeling in the normal hearing group (a, c). Labeling for GluR 2/3 is primarily concentrated in the soma of the neuron in the normal hearing group (arrow in e), however, following deafness the neuropil shows more label (f). Calibration bar $=100 \mu \mathrm{m}$. expression in the current study. Nociceptin receptor knockout mice have a longer recovery period when compared with wild-type mice following noise exposure (Nishi et al. 1997), suggesting a protective role for nociceptin. Serotonin receptors are present in the IC ( $\mathrm{Li}$ et al. 2004), and have a purported role in synaptogenesis (Niitsu et al. 1995) and neuronal plasticity (Julius 1991; Kojic et al. 2000). Many of the differentially expressed neuropeptide-related genes have been implicated in the modulation of GABA, glycine, and/or glutamate receptor function. For example, serotonin receptors (Cai et al. 2002) regulate GABA-A receptor activity. Dopamine can enhance kainate receptor-mediated activity (Knapp and Dowling 1987). In addition, opiates can exert an inhibitory affect on AMPA and kainate receptors (Kolaj and Randic 1996).

\section{Other functionally related groups}

Previous studies of auditory brainstem plasticity found that deafness affects ion channels (Li et al. 2001; Sivaramakrishnan and Oliver 2001; Tzounopoulos and Stackman 2003; von Hehn et al. 2004). We found potassium inwardly rectifying channel, subfamily $\mathrm{J}$, members 4 and 11 decreased at both 3 and 21 days, while the potassium voltage-gated channels, Shal-related family, members 2 and 3 increased at 21 days and the potassium voltage-gated channel, KQT-like subfamily, member 1 decreased in expression at 21 days.

Changes in expression of genes associated with deafnessrelated changes in cell size, dendrites, dendritic spines and synaptic characteristics might be expected. We found the cytoskeleton-related genes Map 2, laminin $\gamma 1$, protein kinase 


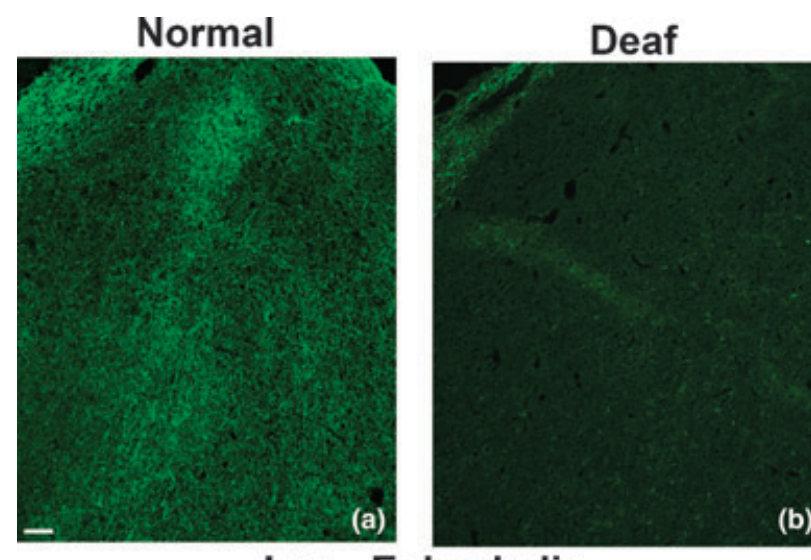

Leu - Enkephalin
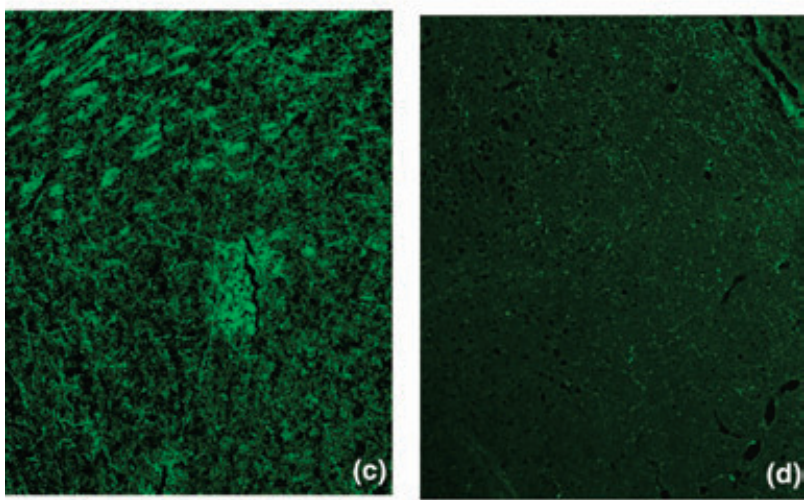

Tyrosine Hydroxylase

Fig. 3 Changes in immunoreactivity for enkephalin $(a, b)$ and tyrosine hydroxylase (c, d) in the central nucleus of the inferior colliculus. Immunoreactivity is decreased in 90-day deaf animals (b, d) when compared with immunoreactivity from normal animals $(a, c)$. Calibration bar $=100 \mu \mathrm{m}$.

2 and 6, and ankyrin all increased in expression, while Map Tau and ARC decreased. Genes involved in vesicular trafficking such as SNAP 25, Munc 13-3, and synaptic vesicle glycoprotein $2 \mathrm{~b}$ increased, while synaptic vesicle glycoprotein 2a decreased in expression.

Several stress-related genes increased in expression and remained increased at 21 days following deafening. These included heat shock proteins 40,60 and 86, as well as caspase 2, nucleostemin, super oxide dismutase 2 , and cyclin (L and G1).

Second messenger-related genes can have direct effects on gene expression and protein production. In this study, the G-protein receptor-related genes endothelin receptor type B, neuropeptide $\mathrm{Y}$ receptor $\mathrm{Y} 1$, neuropeptide $\mathrm{Y}$ receptor $\mathrm{Y}$, and the cannabinoid receptor 1 gene increased at 21 days, and prostaglandin E receptor 4 (subtype EP4), adrenergic receptor, alpha $2 \mathrm{c}$, galanin receptor 1, gonadotropinreleasing hormone receptor, cholecystokinin $\mathrm{B}$ receptor, neurotensin receptor 2, and angiotensin II receptor, type 1 (AT1A) decreased.
Given the many genes differentially expressed, there should also be changes in genes involved in regulation of transcription. We found decreased expression of methyl $\mathrm{CpG}$ binding protein 2 (MeCP2), which normally acts to repress gene transcription. This decreased expression could be coupled to increased transcription of some of its target genes although, in this study, one such target, brain derived neurotrophic factor (BDNF), showed decreased expression. Decreased expression of both BNDF and PENK in the current study is interesting in the context of recent studies which showed that application of an enkephalin agonist increases BDNF expression in frontal cortex and hippocampus (Torregrossa et al. 2004). Bone morphogenetic protein (BMP), an important signaling molecule, is modulated by a group of BMP antagonists. We found increased expression of $\mathrm{BMP}-4 \mathrm{~B}$, along with decreased expression of noggin, one of the major BMP antogonists. Up-regulation of BMP-4B expression and down-regulation of the BMP-antagonist noggin would lead to increased BMP4 signaling through associated SMADs. Other genes in the GO transcriptional regulation classification that increased in expression included cadherin 2, myosin Ib, myelin-associated oligodendrocytic basic protein, and vascular endothelial growth factor receptor. While Delta-like 1 (Drosophila) had decreased expression.

\section{Technical considerations}

We found excellent correspondence in the direction and amount of change with GeneChip analysis and qRT-PCR for most genes at most times following deafness. However, in the 3-day deaf group GABA $\gamma 1$ and glycine $\alpha 2$ receptor subunits showed 33 and $56 \%$ increases, respectively, in the GeneChip analysis, while there was no significant change in either by qRT-PCR. qRT-PCR did show increases in both GABA $\gamma 1$ and glycine $\alpha 2$ receptor subunits at 21 days. In the 21-day deaf group, neurotransmitter-induced early gene protein had only minor expression changes in GeneChip analysis and a $64 \%$ increase and $86 \%$ decrease, respectively, by qRT-PCR. Glycine receptor $\alpha 1$ and $\alpha 3$ subunits did not show significant changes in the GeneChip analysis but showed increases by qRT-PCR, at 21 and 90 days, a modest increase for $\alpha 1$ and large increases for $\alpha 3$. Neurotransmission-related genes often have low levels of constitutive expression and may therefore prove more challenging when trying to detect changes in such genes by GeneChip analysis when compared with qRT-PCR, perhaps a more sensitive measure. We performed qRT-PCR analysis on eight genes with low FDRs, but small changes in expression (ratio less than 1.5) at 3 days following deafness. Six of eight showed greater changes in expression levels by qRT-PCR.

The low constitutive expression of neurotransmissionrelated genes may contribute to the greater variability in intensity levels, as measured by GeneChip analysis. The present study addresses the issue of variability by using an 
increased sample size, using RMA for normalization that more accurately reflects the expression level of genes, as well as using a statistical method sufficiently stringent in assigning significance. We used SAM to compare gene expression of deafened and normal animals, and to calculate the FDR. A surprisingly large number of genes showed FDRs of $5 \%$ or less, suggesting that increased numbers of replicates and RMA can enhance the sensitivity of microarray analysis. Decreasing variability allowed identification of numerous and diverse activity-dependent genes within the inferior colliculus.

We then followed these experiments and analyses with qRT-PCR and immunocytochemical studies for a representative population of our data that we hypothesized would be responsive to decreased activity. Although the specific cell types that undergo modulation as a result of deafness were not differentiated in this examination, we were able to detect changes in both the quantity and intensity of immunolabeling within the central nucleus of the inferior colliculus. The genes that were confirmed with these methods may play an important role in deafness-related plasticity and merit further study in other nuclei within this system. Additionally, many of the other genes identified as differentially expressed in Tables 1-5 and Tables S2 and S3, but not further examined in our study, may also be important and warrant further study.

The present study provides evidence that gene microarrays can provide a useful method for studying deafness-induced plasticity in the central auditory system. By surveying a large pool of neurotransmitter-related genes, we have been able to identify important patterns of expression among these genes. In response to 3 and 21 days of deafness, within the IC, the system seems to compensate for decreased inhibitory input by increasing the expression of highly efficacious inhibitory receptors as well as the molecular machinery necessary for more efficient delivery of these receptors to the synapse. Future studies will include examining different times after deafness as well as studies in additional auditory brainstem regions.

Our results lay the groundwork for future studies that can focus on specific genes, identified in the present study, in greater detail. Certainly, the genes that have not returned to normal levels of expression by the latest time assessed in this study will be of particular interest when considering return of hearing with cochlear prostheses, at different times following deafness. Indeed, there is a correlation between how well a post-lingually deafened patient responds to the cochlear prosthesis and the duration of deafness, with those implanted at earlier times following deafness having the best outcomes (Kileny et al. 1991; Blamey et al. 1992; Gantz et al. 1993). Results of the current study will also provide a normative database and metric to examine reversal at different times following deafness, relationships that have not previously been studied in much detail.

\section{Acknowledgements}

We thank R. D. Griffith, G. Dootz, and the Michigan Comprehensive Diabetes Research and Training Center Microarray Core for technical assistance. This research was supported by the National Institutes of Health grant DC00383 to RAA, grant T32 DC00011 F32DC000479 to AGH, core center grant P30 DC05188 from NIDCD and Cancer Center Support Grant (5 P30 CA46592).

\section{Supplementary material}

The following material is available from:

http://www.blackwellpublishing.com/products/journals/ suppmat/JNC/JNC3090/JNC3090sm.htm

Table S1. Primers used for qRT-PCR.

Table S2. Genes differentially expressed 3 days after deafening.

Table S3. Genes differentially expressed 21 days after deafening.

\section{References}

Akins P. T., Liu P. K. and Hsu C. Y. (1996) Immediate early gene expression in response to cerebral ischemia. Friend or foe? Stroke 27, 1682-1687.

Araki S., Kawano A., Seldon L., Shepherd R. K., Funasaka S. and Clark G. M. (1998) Effects of chronic electrical stimulation on spiral ganglion neuron survival and size in deafened kittens. Laryngoscope 108, 687-695.

Billings P. B., Keithley E. M. and Harris J. P. (1995) Evidence linking the 68-kilodalton antigen identified in progressive sensorineural hearing loss patient sera with heat shock protein 70. Ann. Otol. Rhinol. Laryngol. 104, 181-188.

Blamey P. J., Pyman B. C., Gordon M., Clark G. M., Brown A. M., Dowell R. C. and Hollow R. D. (1992) Factors predicting postoperative sentence scores in postlinguistically deaf adult cochlear implant patients. Ann. Otol. Rhinol. Laryngol. 101, 342-348.

Blanpied T. A., Scott D. B. and Ehlers M. D. (2003) Age-related regulation of dendritic endocytosis associated with altered clathrin dynamics. Neurobiol. Aging 24, 1095-1104.

Bledsoe S. C. Jr, Nagase S., Miller J. M. and Altschuler R. A. (1995) Deafness-induced plasticity in the mature central auditory system. Neuroreport 7, 225-229.

Bobanovic L. K., Royle S. J. and Murrell-Lagnado R. D. (2002) P2X receptor trafficking in neurons is subunit specific. J. Neurosci. 22, 4814-4824.

Cai X., Flores-Hernandez J., Feng J. and Yan Z. (2002) Activitydependent bidirectional regulation of $\operatorname{GABA}(\mathrm{A})$ receptor channels by the 5 -HT(4) receptor mediated signalling in rat prefrontal cortical pyramidal neurons. J. Physiol. 540 (pt 3): 743-759.

Caraiscos V. B., Mihic S. J., MacDonald J. F. and Orser B. A. (2002) Tyrosine kinases enhance the function of glycine receptors in rat hippocampal neurons and human $\alpha(1) \beta$ glycine receptors. J. Physiol. 539, 495-502.

Carvelli L., Moron J. A., Kahlig K. M. et al. (2002) PI 3-kinase regulation of dopamine uptake. J. Neurochem. 81, 859-869.

Caspary D. M., Milbrandt J. C. and Helfert R. H. (1995) Central auditory aging: GABA changes in the inferior colliculus. Exp. Gerontol. 30, 349-360. 
Dodson H. C., Bannister L. H. and Douek E. E. (1994) Effects of unilateral deafening on the cochlear nucleus of the guinea pig at different ages. Brain Res. Dev. Brain Res. 80, 261-267.

Edmonds J. L. Jr, Hoover L. A. and Durham D. (1999) Breed differences in deafferentation-induced neuronal cell death and shrinkage in chick cochlear nucleus. Hear. Res. 127, 62-76.

Gantz B. J., Woodworth G. G., Knutson J. F., Abbas P. J. and Tyler R. S. (1993) Multivariate predictors of audiological success with multichannel cochlear implants. Ann. Otol. Rhinol. Laryngol. 102, 909916.

Garcia M. M., Edward R., Brennan G. B. and Harlan R. E. (2000) Deafferentation-induced changes in protein kinase $\mathrm{C}$ expression in the rat cochlear nucleus. Hear. Res. 147, 113-124.

von Hehn C. A., Bhattacharjee A. and Kaczmarek L. K. (2004) Loss of Kv3.1 tonotopicity and alterations in cAMP response elementbinding protein signaling in central auditory neurons of hearing impaired mice. J. Neurosci. 24, 1936-1940.

Huchton D. M., Pongstaporn T., Niparko J. K. and Ryugo D. K. (1997) Ultrastructural changes in primary endings of deaf white cats. Otolaryngol. Head Neck Surg. 116, 286-293.

Illing R. B. (2001) Activity-dependent plasticity in the adult auditory brainstem. Audiol. Neurootol. 6, 319-345.

Illing R. B. and Michler S. A. (2001) Modulation of P-CREB and expression of c-fos in cochlear nucleus and superior olive following electrical intracochlear stimulation. Neuroreport 12, 875-878.

Illing R. B., Cao Q. L., Forster C. R. and Laszig R. (1999) Auditory brainstem: development and plasticity of GAP-43 mRNA expression in the rat. J. Comp. Neurol. 412, 353-372.

Irizarry R. A., Bolstad B. M., Collin F., Cope L. M., Hobbs B. and Speed T. P. (2003a) Summaries of Affymetrix GeneChip probe level data. Nucleic Acids Res. 31, e15.

Irizarry R. A., Hobbs B., Collin F., Beazer-Barclay Y. D., Antonellis K. J., Scherf U. and Speed T. P. (2003b) Exploration, normalization, and summaries of high density oligonucleotide array probe level data. Biostatistics 4, 249-264.

Julius D. (1991) Molecular biology of serotonin receptors. Annu. Rev. Neurosci. 14, 335-360.

Kazee A. M., Han L. Y., Spongr V. P., Walton J. P., Salvi R. J. and Flood D. G. (1995) Synaptic loss in the central nucleus of the inferior colliculus correlates with sensorineural hearing loss in the C57BL/ 6 mouse model of presbycusis. Hear. Res. 89, 109-120.

Kileny P. R., Zimmerman-Phillips S., Kemink J. L. and Schmaltz S. P. (1991) Effects of preoperative electrical stimulability and historical factors on performance with multichannel cochlear implant. Ann. Otol. Rhinol. Laryngol. 100, 563-568.

Kittler J. T. and Moss S. J. (2003) Modulation of GABAA receptor activity by phosphorylation and receptor trafficking: implications for the efficacy of synaptic inhibition. Curr. Opin. Neurobiol. 13, 341-347.

Kittler J. T., McAinsh K. and Moss S. J. (2002) Mechanisms of GABAA receptor assembly and trafficking: implications for the modulation of inhibitory neurotransmission. Mol. Neurobiol. 26, 251-268.

Knapp A. G. and Dowling J. E. (1987) Dopamine enhances excitatory amino acid-gated conductances in cultured retinal horizontal cells. Nature 325, 437-439.

Kojic L., Dyck R. H., Gu Q., Douglas R. M., Matsubara J. and Cynader M. S. (2000) Columnar distribution of serotonin-dependent plasticity within kitten striate cortex. Proc. Natl Acad. Sci. USA 97, 1841-1844.

Kolaj and Randic (1996) mu-Opioid receptor-mediated reduction of alphaamino-3-hydroxy-5-methyl-4-isoxazolepropionic acid-activated current in dorsal horn neurons. Neurosci. Lett. 204 (1-2): 133-137.

Kotak V. C. and Sanes D. H. (2002) Postsynaptic kinase signaling underlies inhibitory synaptic plasticity in the lateral superior olive. J. Neurobiol. 53, 36-43.
Kungel M., Piechotta K., Rietzel H. J. and Friauf E. (1997) Influence of the neuropeptide somatostatin on the development of dendritic morphology: a cysteamine-depletion study in the rat auditory brainstem. Brain Res. Dev. Brain Res. 101, 107-114.

Lee D. J., Cahill H. B. and Ryugo D. K. (2003) Effects of congenital deafness in the cochlear nuclei of Shaker-2 mice: an ultrastructural analysis of synapse morphology in the endbulbs of Held. J. Neurocytol. 32, 229-243.

Lee S. H., Liu L., Wang Y. T. and Sheng M. (2002) Clathrin adaptor AP2 and NSF interact with overlapping sites of GluR2 and play distinct roles in AMPA receptor trafficking and hippocampal LTD. Neuron 36, 661-674.

Legendre P. (2001) The glycinergic inhibitory synapse. Cell Mol. Life Sci. 58, 760-793.

Lesperance M. M., Helfert R. H. and Altschuler R. A. (1995) Deafness induced cell size changes in rostral AVCN of the guinea pig. Hear. Res. 86, 77-81.

Li Q. H., Nakadate K., Tanaka-Nakadate S., Nakatsuka D., Cui Y. and Watanabe Y. (2004) Unique expression patterns of 5-HT2A and 5-HT2C receptors in the rat brain during postnatal development: Western blot and immunohistochemical analyses. J. Comp. Neurol. 469, 128-140.

Li W., Kaczmarek L. K. and Perney T. M. (2001) Localization of two high-threshold potassium channel subunits in the rat central auditory system. J. Comp. Neurol. 437, 196-218.

Livak K. J. and Schmittgen T. D. (2001) Analysis of relative gene expression data using real-time quantitative PCR and the 2 (-Delta Delta C(T)) method. Methods 25, 402-408.

Lustig L. R., Leake P. A., Snyder R. L. and Rebscher S. J. (1994) Changes in the cat cochlear nucleus following neonatal deafening and chronic intracochlear electrical stimulation. Hear. Res. 74, 29-37.

Malinow R., Mainen Z. F. and Hayashi Y. (2000) LTP mechanisms: from silence to four-lane traffic. Curr. Opin. Neurobiol. 10, 352-357.

Mangin J. M., Guyon A., Eugene D., Paupardin-Tritsch D. and Legendre P. (2002) Functional glycine receptor maturation in the absence of glycinergic input in dopaminergic neurones of the rat substantia nigra. J. Physiol. 542, 685-697.

Mhatre A. N., Li J., Chen A. F., Yost C. S., Smith R. J., Kindler C. H. and Lalwani A. K. (2004) Genomic structure, cochlear expression, and mutation screening of KCNK6, a candidate gene for DFNA4. J. Neurosci. Res. 75, 25-31.

Michler S. A. and Illing R. B. (2003) Molecular plasticity in the rat auditory brainstem: modulation of expression and distribution of phosphoserine, phospho-CREB and TrkB after noise trauma. Audiol. Neurootol. 8, 190-206.

Milbrandt J. C., Holder T. M., Wilson M. C., Salvi R. J. and Caspary D. M. (2000) GAD levels and muscimol binding in rat inferior colliculus following acoustic trauma. Hear. Res. 147, 251-260.

Moller A. R. (2005) Anatomical and Physiological Basis For Neural Plasticity. Neural Plasticity and Disorders of the Nervous System, pp. 1-38. New York: Cambridge University Press.

Moore J. K., Niparko J. K., Perazzo L. M., Miller M. R. and Linthicum F. H. (1997) Effect of adult-onset deafness on the human central auditory system. Ann. Otol. Rhinol. Laryngol. 106, 385-390.

Mossop J. E., Wilson M. J., Caspary D. M. and Moore D. R. (2000) Down-regulation of inhibition following unilateral deafening. Hear. Res. 147, 183-187.

Myers M. W., Quirk W. S., Rizk S. S., Miller J. M. and Altschuler R. A. (1992) Expression of the major mammalian stress protein in the rat cochlea following transient ischemia. Laryngoscope 102, 981987.

Niitsu Y., Hamada S., Hamaguchi K., Mikuni M. and Okado N. (1995) Regulation of synapse density by 5-HT2A receptor agonist and 
antagonist in the spinal cord of chicken embryo. Neurosci. Lett. 195, 159-162.

Niparko J. K. (1999) Activity influences on neuronal connectivity within the auditory pathway. Laryngoscope 109, 1721-1730.

Niparko J. K. and Finger P. A. (1997) Cochlear nucleus cell size changes in the dalmatian: model of congenital deafness. Otolaryngol. Head Neck Surg. 117, 229-235.

Nishi M., Houtani T., Noda Y. et al. (1997) Unrestrained nociceptive response and disregulation of hearing ability in mice lacking the nociceptin/orphaninFQ receptor. EMBO J. 16, 1858-1864.

Nishiyama N., Hardie N. A. and Shepherd R. K. (2000) Neonatal sensorineural hearing loss affects neurone size in cat auditory midbrain. Hear. Res. 140, 18-22.

Niu X., Bogdanovic N. and Canlon B. (2004) The distribution and the modulation of tyrosine hydroxylase immunoreactivity in the lateral olivocochlear system of the guinea-pig. Neuroscience. 125(3), 725-733.

Oh S. H., Yu W. S., Song B. H., Lim D., Koo J. W., Chang S. O. and Kim C. S. (2000) Expression of heat shock protein 72 in rat cochlea with cisplatin-induced acute ototoxicity. Acta Otolaryngol. 120, 146-150.

Ohlemiller K. K. and Dugan L. L. (1999) Elevation of reactive oxygen species following ischemia-reperfusion in mouse cochlea observed in vivo. Audiol. Neurootol. 4, 219-228.

Ohlemiller K. K., McFadden S. L., Ding D. L., Flood D. G., Reaume A. G., Hoffman E. K., Scott R. W., Wright J. S., Putcha G. V. and Salvi R. J. (1999) Targeted deletion of the cytosolic $\mathrm{Cu} / \mathrm{Zn}$ superoxide dismutase gene (Sod1) increases susceptibility to noiseinduced hearing loss. Audiol. Neurootol. 4, 237-246.

Okamoto P. M., Gamby C., Wells D., Fallon J. and Vallee R. B. (2001) Dynamin isoform-specific interaction with the shank/ProSAP scaffolding proteins of the postsynaptic density and actin cytoskeleton. J. Biol. Chem. 276, 48 458-48 465.

Passafaro M., Piech V. and Sheng M. (2001) Subunit-specific temporal and spatial patterns of AMPA receptor exocytosis in hippocampal neurons. Nat. Neurosci. 4, 917-926.

Piechotta K., Weth F., Harvey R. J. and Friauf E. (2001) Localization of rat glycine receptor $\alpha 1$ and $\alpha 2$ subunit transcripts in the developing auditory brainstem. J. Comp. Neurol. 438, 336-352.

Potashner S. J., Suneja S. K. and Benson C. G. (2000) Altered glycinergic synaptic activities in guinea pig brain stem auditory nuclei after unilateral cochlear ablation. Hear. Res. 147, 125-136.

Rajan R., Irvine D. R., Wise L. Z. and Heil P. (1993) Effect of unilateral partial cochlear lesions in adult cats on the representation of lesioned and unlesioned cochleas in primary auditory cortex. J. Comp. Neurol. 338, 17-49.

Raza A., Milbrandt J. C., Arneric S. P. and Caspary D. M. (1994) Agerelated changes in brainstem auditory neurotransmitters: measures of GABA and acetylcholine function. Hear. Res. 77, 221-230.

Robertson D., Harvey A. R. and Cole K. S. (1989) Postnatal development of the efferent innervation of the rat cochlea. Brain Res. Dev. Brain Res. 47, 197-207.

Russell F. A. and Moore D. R. (2002) Ultrastructural transynaptic effects of unilateral cochlear ablation in the gerbil medial superior olive. Hear. Res. 173, 43-61.

Ryugo D. K., Pongstaporn T., Huchton D. M. and Niparko J. K. (1997) Ultrastructural analysis of primary endings in deaf white cats: morphologic alterations in endbulbs of Held. J. Comp. Neurol. 385, 230-244.

Sato K., Shiraishi S., Nakagawa H., Kuriyama H. and Altschuler R. A. (2000) Diversity and plasticity in amino acid receptor subunits in the rat auditory brain stem. Hear. Res. 147, 137-144.

Schweizer C., Balsiger S., Bluethmann H., Mansuy I. M., Fritschy J. M., Mohler H. and Luscher B. (2003) The $\gamma 2$ subunit of GABA(A) receptors is required for maintenance of receptors at mature synapses. Mol. Cell Neurosci. 24, 442-450.

Shi S., Hayashi Y., Esteban J. A. and Malinow R. (2001) Subunitspecific rules governing AMPA receptor trafficking to synapses in hippocampal pyramidal neurons. Cell 105, 331-343.

Shi X., Ren T. and Nuttall A. L. (2002) The electrochemical and fluorescence detection of nitric oxide in the cochlea and its increase following loud sound. Hear. Res. 164, 49-58.

Sie K. C. and Rubel E. W. (1992) Rapid changes in protein synthesis and cell size in the cochlear nucleus following eighth nerve activity blockade or cochlea ablation. J. Comp. Neurol. 320, 501-508.

Sivaramakrishnan S. and Oliver D. L. (2001) Distinct K currents result in physiologically distinct cell types in the inferior colliculus of the rat. J. Neurosci. 21, 2861-2877.

Storey N. M., O’Bryan J. P. and Armstrong D. L. (2002) Rac and Rho mediate opposing hormonal regulation of the ether-a-go-go-related potassium channel. Curr. Biol. 12, 27-33.

Syka J. (2002) Plastic changes in the central auditory system after hearing loss, restoration of function, and during learning. Physiol. Rev. 82, 601-636.

Takahashi T., Momiyama A., Hirai K., Hishinuma F. and Akagi H. (1992) Functional correlation of fetal and adult forms of glycine receptors with developmental changes in inhibitory synaptic receptor channels. Neuron 9, 1155-1161.

Torregrossa M. M., Isgor C., Folk J. E., Rice K. C., Watson S. J. and Woods J. H. (2004) The $\delta$-opioid receptor agonist (+)BW373U86 regulates BDNF mRNA expression in rats. Neuropsychopharmacology 29, 649-659.

Tusher V. G., Tibshirani R. and Chu G. (2001) Significance analysis of microarrays applied to the ionizing radiation response. Proc. Natl Acad. Sci. USA 98, 5116-5121.

Tzounopoulos T. and Stackman R. (2003) Enhancing synaptic plasticity and memory: a role for small-conductance $\mathrm{Ca}(2+)$-activated $\mathrm{K}+$ channels. Neuroscientist 9, 434-439.

Vale C. and Sanes D. H. (2000) Afferent regulation of inhibitory synaptic transmission in the developing auditory midbrain. J. Neurosci. 20, 1912-1921.

Vale C. and Sanes D. H. (2002) The effect of bilateral deafness on excitatory and inhibitory synaptic strength in the inferior colliculus. Eur. J. Neurosci. 16, 2394-2404.

Van Campen L. E., Murphy W. J., Franks J. R., Mathias P. I. and Toraason M. A. (2002) Oxidative DNA damage is associated with intense noise exposure in the rat. Hear. Res. 164, 29-38.

Verstreken M., Claes J. and Van de Heyning P. H. (1996) Osteogenesis imperfecta and hearing loss. Acta Otorhinolaryngol. Belg. 50, 9198.

Wang J., Salvi R. J. and Powers N. (1996) Plasticity of response properties of inferior colliculus neurons following acute cochlear damage. J. Neurophysiol. 75, 171-183.

Wang X. W., Wang X. J., Song J. S., Chen H. X. and Man Y. H. (2002) Influence of evoked HSP70 expression on hearing function of the cochlea in guinea pigs. Di Yi Jun Yi Da Xue Xue Bao 22, 922-924.

Willott J. F. and Bross L. S. (1996) Morphological changes in the anteroventral cochlear nucleus that accompany sensorineural hearing loss in DBA/2J and C57BL/6J mice. Brain Res. Dev. Brain Res. 91, 218-226.

Yeom K., Gray J., Nair T. S., Arts H. A., Telian S. A., Disher M. J., El-Kashlan H., Sataloff R. T., Fisher S. G. and Carey T. E. (2003) Antibodies to HSP-70 in normal donors and autoimmune hearing loss patients. Laryngoscope 113, 1770-1776.

Zhang J., Suneja S. K. and Potashner S. J. (2004) Protein kinase A and calcium/calmodulin-dependent protein kinase II regulate glycine and GABA release in auditory brain stem nuclei. J. Neurosci. Res. 75, 361-370. 